\title{
An Approach for Resilient-Green Supplier Selection Based on WASPAS, BWM, and TOPSIS under Intuitionistic Fuzzy Sets
}

\author{
Lei Xiong, ${ }^{1}$ Shuqi Zhong, ${ }^{2}$ Sen Liu $\mathbb{D}^{3}{ }^{3}$ Xiao Zhang, ${ }^{4}$ and Yanfeng Li $\mathbb{D}^{5}$ \\ ${ }^{1}$ School of Economics and Management, Yunnan Normal University, Kunming 650500, Yunnan, China \\ ${ }^{2}$ International Business School, Yunnan University of Finance and Economics, Kunming 650221, China \\ ${ }^{3}$ School of Logistics, Yunnan University of Finance and Economics, Kunming 650221, China \\ ${ }^{4}$ School of International Trade and Economics, University of International Business and Economic, Beijing 100029, China \\ ${ }^{5}$ Business School, Yunnan University of Business Management, Kunming 650106, China \\ Correspondence should be addressed to Yanfeng Li; lyf@ynufe.edu.cn
}

Received 23 February 2020; Revised 12 May 2020; Accepted 18 May 2020; Published 22 July 2020

Guest Editor: Zaoli Yang

Copyright (c) 2020 Lei Xiong et al. This is an open access article distributed under the Creative Commons Attribution License, which permits unrestricted use, distribution, and reproduction in any medium, provided the original work is properly cited.

\begin{abstract}
The green supply chain management (GSCM) is an enterprise's effort to protect the environment and a key way to achieve sustainable environmental development. On the contrary, globalization brings more risks to the supply chain. Resilience has become a critical definition in supply chain management to help enterprises review the disruption and return to normal state. Therefore, choosing a resilient-green supplier to build a supply chain environment with flexibility and greenness under interruption becomes necessary for research works. However, the existing studies tended to focus on only one of the factors with resilience and greenness, and no comprehensive criteria system and performance value is expressed by a crisp number. Therefore, this paper proposes a hybrid method which integrates the Best-Worst method (BWM), Weighted Aggregated Sum-Product Assessment (WASPAS), and Technique for Order Preference by Similarity to Ideal Solution (TOPSIS) to solve the critical problems. Firstly, BWM is used to weigh the criteria; secondly, intuitionistic fuzzy numbers are introduced into the ranking stage. Then, the integrated WASPAS and TOPSIS are used to rank the alternatives to select the optimal resilient-green supplier. Finally, an illustrative example proves the feasibility of this method.
\end{abstract}

\section{Introduction}

With the environment adverse changes, green supply chain management (GSCM) emerged as the times when enterprises and products needed to adapt to the characteristic of resource-efficient and environment-friendly. GSCM required collaboration between the upstream and downstream enterprises in the supply chain, integrating efficient and green concepts into key nodes of product design, production, packaging, transportation, marketing, and recycling [1]. Core enterprises should be responsible not only for their own actions but also for the negative environmental impact of upstream and downstream enterprises. Therefore, the supplier selection has become the key issue of green supply chain coordination [2]. It is also a critical way for enterprises to gain competitiveness under the environment-friendly trend and policy.
Due to the globalization of the supply chain, logistics and information flow are facing the fluctuation risk brought by the disruptions, which are mainly caused by the natural disasters, man-made disasters, and technological threats. GSCM was confronted with similar problems. How to simultaneously weaken the impact of the supply chain on the environment and improve the ability to respond to disruptions has become a critical issue to be solved urgently in the supply chain management. Integrating resilient practice into the green supply chain can deal with the disaster-related uncertainty, reduce the quality fluctuation in green raw materials, and effectively avoid the logistics interruption in product transportation, marketing, and recycling.

Therefore, it is a new challenge for managers to construct the supply chain that can operate in the environment of green policy and respond to the disruptions in time when disasters occur. In the resilient-GSCM, the supplier selection 
is the key way to achieve the goal. At present, the relationship between the resilience and green was established in supply chain management [3-5]. Several research studies have also discussed the resilient supplier selection [6-10] and green supplier selection [1, 11-14]. However, few studies considered both the resilience and greenness factors in supplier selection problems. Thus, a decision-making method was proposed for selecting suppliers that can take both environmental problems and disruption risks for further research studies into account.

Supplier selection is a typical multicriteria group decision-making (MCGDM) problems. The MCGDM always consists of three research fields $[15,16]$ : expert weighting methods, criteria weighting methods, and aggregation operators. The studies of expert weighting methods and criteria weighting methods are mainly concentrating on the computation of the weights of the experts and criteria and which are often obtained by decision makers directly based on experiences and preferences [17] or worked out by the decision matrix [18-20]. The aggregation operators are mainly focused on the conversion process of the collective decision matrix to the integrated evaluate values of alternatives with the weights of the experts and criteria in various aggregation methods [21, 22], and then rank the alternatives. Scholars usually focus on one or two fields in MCGDM, and few studies researched these all three ways simultaneously in one article due to the huge amount of work, for example, some research studies only focus on criteria weighting methods [23, 24] or aggregation operators [21, 25]. Wu et al. [26] focus on both experts and criteria weighting methods. Zavadskas et al. [27] discussed the optimization of criteria weighting and aggregation operator.

Through literature review, it was found that there were several limitations in terms of the resilient-green supplier selection. Firstly, few studies focused on the resilient-green supplier selection. According to the green manufacturing process and resilience-related characteristics, the resiliencegreenness criteria system was constructed; secondly, the language terms used in many MCGDM problems were not in line with the expression habits of decision makers and reduced the accuracy of decision-making process; thirdly, the traditional weighting methods (such as AHP) of MCGDM had more steps to compare, so the calculation process was more complicated; lastly, the single MCGDM method made the alternatives' ranking inaccurate and inconsistent.

Therefore, in order to fill the research gap, a novel method, which integrated WASPAS, BWM, and TOPSIS based on intuitionistic fuzzy numbers, was proposed to select the resilient-green supplier under the supply chain environment. The reasons of why we integrate these techniques in our method are mainly based on the following three ways. (1) Compared with triangle fuzzy number and trapezoid fuzzy number (only can represent one grade of membership that is crisp in the unit interval), intuitionistic fuzzy number can reflect more grades of membership, that is, membership degree, nonmembership degree, and hesitation degree [28]. The hesitation degree represents the definition of "neither this nor that" [29]. Intuitionistic fuzziness has more advantages in reflecting fuzziness and uncertainty in the decision matrix. Therefore, our research is conducted in the intuitionistic fuzzy environment. (2) BWM simplifies the calculation steps, and the weighting results are more consistent than the traditional AHP [30]. Therefore, BWM is selected as the method of criteria weighting in this study. The integrated WASPAS and TOPSIS methods make up for the instability of traditional WASPAS due to the change of parameter value, improving the accuracy and certainty of decision results [31]. Hence, we integrate BWM, WASPAS, and TOPSIS techniques to become a new MCGDM approach, which has advantages that a single classical approach does not. (3) As mentioned above, the research of MCGDM is mainly divided into three aspects, and few studies researched these entire three ways at the same time in one article due to the amount of work. In this study, we focus on the improvement of criteria weighting process, and the aggregation operators are not our focus. Hence, through literature review, we find that the intuitionistic Fuzzy Weighted Averaging (IFWA) and Intuitionistic Fuzzy Ordered Weighted Averaging (IFOWA) proposed by $\mathrm{Xu}$ [32] are applicable to different situations with intuitionistic fuzzy sets. Besides, IFWA is more appropriate for the research of the weighting methods for criteria in intuitionistic fuzzy sets [33]. Hence, we choose IFWA operator [32] as the aggregation operator to aggregate the decision information in this study, due to the advantages of logical [34, 35], easy to operate [36], and highly recognized [33, 37].

This paper consists of seven parts. Section 1 is an introduction, Section 2 presents the literature review, and the construction of the criteria system appears in Section 3. Section 4 introduces some basic definitions about the decision method. In Section 5, a hybrid MCGDM method is proposed, and the feasibility of the method is verified by an illustrative example in Section 7. Finally, the conclusion of the whole paper is presented in Section 8 .

\section{Literature Review}

GSCM was part of the efforts of organizations and researchers to respond to environmental awareness and sustainable development policies [13]. The implementation of GSCM could protect the environment, save resources, and enhance the competitiveness of supply chain enterprises. Therefore, GSCM has become a more popular definition.

With the increase of public awareness and pressure from the governments, researchers paid more attention on the GSCM and much related works have been performed. For example, Handfield et al. [38] defined GSCM for the first time, incorporating environmental factors into customer orders cycle for design, procurement, manufacturing, assembly, packaging, logistics, and distribution activities. Zhu et al. [39] improved the definition and put forward that the purpose of implementing green supply chain was to help enterprises obtain profits and market share. After that scholars mainly defined the GSCM from the aspects of green practices and principles, emphasizing the integration of environmental dimension/issues into supply chain 
management in order to achieve environmental performance [40-44] and involving a series of green measures throughout the product's life cycle, including product design, material selection and procurement, manufacturing process, delivery of the final products, marketing, reverse logistics, and end-of-life management [45-50]. In the past two decades, many studies have focused on the green supplier evaluation and selection. Handfield et al. [51] introduced environmental factors into the supplier evaluation criteria and calculated them with the analytic hierarchy process (AHP). Tsai and Hung [52] constructed an evaluation model from the perspective of performance to help enterprises manage and monitor green supply chain. Akman [53] clustered suppliers according to criteria-delivery, quality, cost, and service by c-means clustering method and finally used VIKOR to rank the green suppliers. Lo et al. [12] constructed the criteria system of performance, environmental protection, and risk, combining MCGDM and FMOLP to solve the problem of green supplier selection and order allocation. Peng et al. [54] established evaluation criteria from three aspects of economy, environment, and society, determined the criteria weight in the picture fuzzy environment, and selected more sustainable suppliers.

Global supply chains enabling the interrelated business activities were handled around the world in a decentralized way; thus, enterprises could reduce the production costs and achieve profits by finding competitive partners [55]. In the globalization environment, natural disasters (floods and earthquakes), man-made disasters (fires, traffic accidents, and terrorist attacks), and technological threats (technology leaks) would lead to the fluctuation and interruption in supply chains [56-58]. Increasing supply chain resilient practice and choosing more resilient suppliers were effective ways to avoid the interruption. Holling [59] first proposed the concept of resilience and pointed out it was the special ability to absorb change. With the application of resilience in the supply chain, the resilient supply chain emerged as a new concept [60]. Ponomarov and Holcomb [61] defined it as "the adaptive capability of the supply chain to prepare for unexpected events, respond to disruptions, and function." Other definition focused on the ability of enterprises to recover normal operation after interruption [62, 63]. At present, resilience could be improved from two aspects: (1) improving the supply chain (e.g., creating redundancies, increasing flexibility, and changing the corporate culture) [64] and (2) selecting resilient supplier (before, during, and after disruption) [8]. Parkouhi and Ghadikolaei [10] used the grey VIKOR method to evaluate the rating of resilient suppliers by referring to the opinions of paper industry experts, and the criteria system was constructed from four dimensions of the benefits, opportunities, costs, and risks. Rajesh and Ravi [65] determined the criteria and its subcriteria from five aspects: primary performance factors, responsiveness, risk deduction, technical support, and sustainability, then ranked resilient suppliers with the grey relational analysis method.

In the field of supply chain management, resilience and greenness have already been linked. Azevedo et al. [66] took the automobile enterprises and supply chain as the research background by using the integrated assessment model to evaluate the greenness and resilience index. The results showed that enhancing resilience was conducive to improve the supply chain competitiveness, while green practice mainly affected the environment. Sonia et al. [67] designed the supply chain by integrating the ecologically sustainability and resilience based on the carbon footprint and emission, via the usage of the fuzzy AHP, TOPSIS, and multiobjective optimization method. Fahimnia and Jabbarzadeh [68] constructed a novel multiobjective optimization model and discussed the relationship between the sustainability and resilience at the level of supply chain design. Based on the research studies of drug supply chain design, Zahiri et al. [69] proposed a new stochastic fuzzy goal programming for the problem of model uncertainty and case analysis of the Truvada supply chain in the French LGBTQ community. Mohammed et al. [4] proposed a fuzzy multiobjective programming model to achieve a resilient and green supply chain design approach, which could reduce the supply chain costs and environmental impact and, moreover, extend the value of resilience. Yavari and Zaker [5] proposed a comprehensive model of the two-layered network structure to improve the design in the resilient-green closed-loop supply chain for the power network interruption to the perishable product supply chain and ultimately expected to achieve low cost and low carbon emissions in the supply chain. However, the concept of resilient green was often used for supply chain design in different industries, with only few relevant research studies for supplier selection. As the main external risk, the supplier selection with the scientific decision-making method could effectively improve the supply chain. The disruption would hinder the green development goal, and the relevant research on resilient-green supply chain is essential.

The supplier selection belonged to the category of multicriteria group decision-making (MCGDM) problem, which was usually divided into multiattribute group decision-making (MAGDM) (solution space is discrete) and multiobjective decision-making (MODM) (solution space is continuous) [70]. MAGDM as a classic solution, included TOPSIS [71], AHP [72], Analytic Network Process (ANP) [73], VIKOR [74], BWM [30], Weighted Aggregated SumProduct Assessment (WASPAS) [75], the decision-making trial and evaluation laboratory (DEMATEL), preference ranking organization method for enrichment evaluation (PROM-ETHEE), and the elimination and choice translating reality (ELECTRE) [76].

The recent existing studies about resilient-green supplier selection methods mainly focused on three aspects. (1) MCGDM-based methods: the comprehensive ranking of suppliers was obtained by evaluating multiple criteria of several alternatives. Common MCGDM methods included TOPSIS [77, 78], VIKOR [79], AHP [80], BWM [78], WASPAS [81], and DEMATEL [82]. (2) Artificial intelligence (AI)-based methods: this method could simulate the decision-making behavior of experts accurately by analyzing a large amount of past data through computer programs, including neural network method [83], case-based reasoning, and genetic algorithm [84]. (3) Hybrid methods: these 
methods supported experts to integrate any of the two methods, so as to make up for the shortcomings of the single method. For example, fuzzy BWM-VIKOR [26], fuzzy AHPTOPSIS [85], fuzzy Entropy-TOPSIS [14], BWM-DEMATEL-TOPSIS [86], and MABAC-ELECTRE [55]. The comparison of this study with previous studies on dimensions and approaches are shown in Table 1.

Literatures review showed that there were still some limitations in the resilient-green supplier selection. (1) Resilience and greenness have been linked in the application of the supply chain. Scholars also considered that the links could promote the supply chain sustainability. However, most of the existing research studies focused on the supply chain design and lacked relevant literature to improve the resilient-green supply chain from the perspective of supplier selection. As the main source of supply chain external conflict, choosing the resilient-green supplier scientifically has become a necessary research object. (2) Decision makers' opinions were difficult to express accurately with language, which affected the accuracy of criteria weighting and alternatives ranking. (3) The single MCGDM method was difficult to improve the alternatives ranking and could not work out the consistency of result.

Therefore, a criteria system for the resilient-green supplier selection based on the literature review of the green/ resilient supply chain was proposed in order to fill the research gap, which integrated BWM, WASPAS, and TOPSIS into the proposed method. BWM was used in the process of weighting the criteria weight as a foolproof method. The TOPSIS method was integrated into WASPAS with intuitionistic fuzzy sets to make the final alternative as close as possible to the positive ideal solution (PIS). Finally, the novel method's effectiveness was verified by an example.

\section{The Criteria of Resilient-Green Supplier Selection}

The number of studies on green supplier selection was increasing $[1,4,12,13,81]$. However, the previous research studies ignored the green supplier selection under the disruption environment. At present, the government's requirements for environmental protection continue to spread to various industries. The supply chain exhibits a global trend, and it is increasingly important to develop effective measures to prevent the disruption of natural disasters. In this case, construction of the criteria system for resilientgreen supplier selection becomes a critical branch in supplier selection.

From the perspective of integrating production process and green supply chain practices [88], the green supplier selection criteria were proposed. Green products production mainly includes design, raw material procurement, manufacturing, distribution, marketing, recycling, life cycle management, and other processes. According to practices related to each process, it is believed that the following factors should be considered. Eco-design (design) was recognized by many scholars as a prerequisite with the purpose of reducing the negative impact on the environment [89-91], which could determine the trend of greenness of products. Green procurement (raw material procurement) reflects the environmental action taken by suppliers in response to the environmental protection [77]. The pollution production and green packing (manufacturing) are two processes in manufacturing. The control of harmful substance emissions can directly affect the greenness, while green packaging is related to the recycling logistics network. Green image (marketing), as an assessment of supplier's past efforts for environmental protection, has attracted the attention of many scholars $[1,11,13]$. Life cycle management refers to the supplier's management ability and level of each process in terms of the cost, energy use, and process design.

Considering disruption from the three aspects of before, during, and after is a comprehensive view. This paper discusses the capabilities that resilient supplier should have from the two dimensions of vulnerability and recovery to build selection metrics. Vulnerability emphasized the preparation of the system before the occurrence of disasters, and recovery referred to the absorption capacity of the system during the disaster and the recovery ability after the disaster $[92,93]$. The four indicators were used to select the resilient suppliers according to [8], namely, surplus inventory (vulnerability), factory segregation (vulnerability), reliability (vulnerability), and reorganization (recovery).

In the process of building the criteria system, there is an interactive part of resilience and greenness. The criteria part as coincident criteria is proposed, which acts on the resilientgreen supplier selection in three aspects. Table 2 provides a detailed description of the criteria, definition, and references of resilient-green supplier selection.

\section{Preliminaries}

\subsection{Intuitionistic Fuzzy Set}

Definition 1 (see [101]). Let $\tilde{a}$ be a fuzzy set in the universe of discourse $X$, and $\mu_{\widetilde{a}}$ is a membership function $\mu_{\widetilde{a}}: X \longrightarrow[0,1]$, where $\mu_{\widetilde{a}}(x) \leq 1 \forall x$. Fuzzy set can be represented in the following way:

$$
\tilde{a}=\left\{\left\langle x, \mu_{\widetilde{a}}(x)\right\rangle: x \in X\right\} .
$$

Definition 2 (see [102]). Let $\widetilde{a}$ be an fuzzy set in the universe of discourse $X$, where $\mu_{\widetilde{a}}$ is a membership function $\mu_{\widetilde{a}}: X \longrightarrow[0,1], \quad v_{\widetilde{a}}$ is a nonmembership function $v_{\widetilde{a}}: X \longrightarrow[0,1]$, and $0 \leq \mu_{\widetilde{a}}+v_{\widetilde{a}} \leq 1$. Intuitionistic fuzzy set can be represented in the following way:

$$
\widetilde{a}=\left\{\left\langle x, \mu_{\widetilde{a}}(x), v_{\widetilde{a}}(x)\right\rangle: x \in X\right\} .
$$

$\pi_{\widetilde{a}}(x)$ is called the hesitancy degree of $x$ to $\tilde{a}$, where $0 \leq \pi_{\widetilde{a}}(x) \leq 1$. When $\pi_{\widetilde{a}}(x)=0$, the intuitionistic fuzzy set should turn into a traditional fuzzy set:

$$
\pi_{\widetilde{a}}(x)=1-\mu_{\widetilde{a}}(x)-v_{\widetilde{a}}(x) .
$$

Definition 3 (see [102]). Let $\tilde{a}$ and $\widetilde{b}$ be IFSs of the universe $X$, and the addition and multiplication of $\widetilde{a}$ and $\widetilde{b}$ are as follows: 
TABLE 1: Comparison of this study with previous studies.

\begin{tabular}{|c|c|c|c|c|}
\hline \multirow{2}{*}{ Literature } & \multicolumn{2}{|c|}{ Dimensions } & \multirow{2}{*}{ Approach } & \multirow{2}{*}{ Theme } \\
\hline & Resilience & Greenness & & \\
\hline Kuo et al. [83] & & $\sqrt{ }$ & $\begin{array}{l}\text { Artificial neural network (ANN) + data } \\
\text { envelopment analysis (DEA) + analytic } \\
\text { network process (ANP) }\end{array}$ & $\begin{array}{c}\text { The integration results of the three methods are } \\
\text { better than two other hybrid methods, } \\
\text { ANN-DEA and ANP-DEA }\end{array}$ \\
\hline $\begin{array}{l}\text { Zouggari and } \\
\text { Benyoucef }[85]\end{array}$ & & $\sqrt{ }$ & Fuzzy AHP + fuzzy TOPSIS & $\begin{array}{c}\text { Solving order allocation problem with fuzzy } \\
\text { TOPSIS }\end{array}$ \\
\hline Hashemi et al. [87] & & $\sqrt{ }$ & $\begin{array}{c}\text { Grey relational analysis (GRA) + analytic } \\
\text { network process (ANP) }\end{array}$ & ANP improves the uncertainty in GRA \\
\hline $\begin{array}{l}\text { Hosseini and } \\
\text { Khaled [8] }\end{array}$ & $\sqrt{ }$ & & $\begin{array}{c}\text { Classification and regression tree (CART)+ } \\
\text { neural network }(\mathrm{NN})+\text { analytic hierarchy } \\
\text { process }(\mathrm{AHP})\end{array}$ & $\begin{array}{l}\text { Hybrid methods with different categories have } \\
\text { better prediction resilience than single- } \\
\text { category methods }\end{array}$ \\
\hline $\begin{array}{l}\text { Parkouhi and } \\
\text { Ghadikolaei [10] }\end{array}$ & $\sqrt{ }$ & & Analytic network process (ANP) + VIKOR & $\begin{array}{c}\text { Application of grey number and fuzzy set in } \\
\text { model }\end{array}$ \\
\hline Amindoust [56] & $\sqrt{ }$ & $\sqrt{ }$ & Assurance region DEA method (AR-DEA) & $\begin{array}{l}\text { Combining sustainable criteria with resilient } \\
\text { criteria in supplier selection }\end{array}$ \\
\hline Demir et al. [79] & & $\sqrt{ }$ & $\begin{array}{l}\text { VIKOR-based sorting method } \\
\text { (VIKORSORT) }\end{array}$ & $\begin{array}{l}\text { VIKORSORT can be used to sort green } \\
\text { suppliers into the predefined ordered classes } \\
\text { Introducing TOPSIS into ranking stage of }\end{array}$ \\
\hline Proposed method & $\sqrt{ }$ & $\sqrt{ }$ & BWM + fuzzy WASPAS + fuzzy TOPSIS & $\begin{array}{l}\text { WASPAS can improve the accuracy and } \\
\text { consistency }\end{array}$ \\
\hline
\end{tabular}

TABLE 2: Criteria for resilient-green supplier selection.

\begin{tabular}{|c|c|c|}
\hline Criteria of greenness & Definition & References \\
\hline$G_{1}$ Eco-design & $\begin{array}{c}\text { Product materials are easy to recycle and reuse, using as little material and energy as possible, thus } \\
\text { reducing the impact on the environment }\end{array}$ & {$[14,94]$} \\
\hline$G_{2}$ Green procurement & $\begin{array}{c}\text { Purchasers are trained to purchase raw materials in accordance with green principles } \\
\text { (environmentally friendly and harmless), and purchasers can communicate with product designers } \\
\text { in a timely manner }\end{array}$ & [78] \\
\hline$G_{3}$ Pollution production & Air pollution, liquid waste, solid waste, and harmful materials produced per unit of products & {$[13,95]$} \\
\hline$G_{4}$ Green packing & reen packaging meets the $4 \mathrm{R} 1 \mathrm{D}$ principle: reduce, reuse, reclaim, recycle and degradable & [96] \\
\hline$G_{5}$ Green image & $\begin{array}{l}\text { Ability to produce products in accordance with green principles and the proportion of consumers } \\
\text { accepting green products }\end{array}$ & {$[1,97]$} \\
\hline $\begin{array}{l}G_{6} \text { Life cycle } \\
\text { management }\end{array}$ & $\begin{array}{l}\text { Management (cost control, process design, and energy use) of the green products life cycle } \\
\text { including design, material selection, manufacturing, marketing, and logistics }\end{array}$ & {$[1]$} \\
\hline \multicolumn{3}{|l|}{ Criteria of resilience } \\
\hline$S_{1}$ Surplus inventory & $\begin{array}{l}\text { Under the disruption environment, surplus inventory can make up for production interruption, } \\
\text { which can effectively temporarily prevent supply chain breakdown }\end{array}$ & {$[8]$} \\
\hline$S_{2}$ Factory segregation & $\begin{array}{c}\text { Enterprises has scattered and spare factory, each factory has the same technical conditions and } \\
\text { material reserves in order to make up for production activities quickly }\end{array}$ & {$[56]$} \\
\hline$S_{3}$ Reliability & $\begin{array}{l}\text { Establish good cooperative relationship with partners with recognition; enterprises can provide } \\
\text { materials and services in time, accounts are clear and true, and disruption cost is known }\end{array}$ & {$[60]$} \\
\hline$S_{4}$ Reorganization & Ability to integrate resources rapidly and reconstruct corporate culture and organization & [8] \\
\hline \multicolumn{3}{|l|}{ Coincident criteria } \\
\hline$O_{1}$ Logistics & $\begin{array}{c}\text { Greenness: planning reasonable transport routes to reduce } \mathrm{CO}_{2} \text { emissions; setting up recycling } \\
\text { logistics, realizing the packaging reuse, and scientifically integrating this route into delivery route; } \\
\text { use of new-energy vehicles } \\
\text { Resilience: change the delivery route and implement the mode of multimodal transport rapidly } \\
\text { when the original route is impacted }\end{array}$ & {$[98,99]$} \\
\hline $\mathrm{O}_{2}$ Warehousing & $\begin{array}{l}\text { Greenness: building materials are environmentally friendly, recyclable, and do not release harmful } \\
\text { gases; classified warehousing of different products, rational layout of warehousing space, and } \\
\text { avoiding production circuitous transportation } \\
\text { Resilience: the warehouse is made of antiseismic and sunscreen building materials to provide } \\
\text { physical protection for products in the natural disasters }\end{array}$ & {$[100]$} \\
\hline $\begin{array}{l}\mathrm{O}_{3} \text { Cooperation } \\
\text { commitment }\end{array}$ & $\begin{array}{l}\text { Greenness: managers actively take green initiatives; signing environmental commitment among } \\
\text { partners to form green supply chain upstream and downstream linkages } \\
\text { Resilience: enterprises have scheduled backup suppliers and establish contract relationship with } \\
\text { backup suppliers in time when interrupting cooperation with other suppliers }\end{array}$ & {$[14,100]$} \\
\hline
\end{tabular}




$$
\begin{aligned}
& \tilde{a} \oplus \widetilde{b}=\left\{\left\langle\mu_{\widetilde{a}}(x)+\mu_{\widetilde{b}}(x)-\mu_{\widetilde{a}}(x) \mu_{\widetilde{b}}(x), v_{\widetilde{a}}(x) v_{\widetilde{b}}(x)\right\rangle: x \in X\right\}, \\
& \widetilde{a} \otimes \widetilde{b}=\left\{\left\langle\mu_{\widetilde{a}}(x) \mu_{\widetilde{b}}(x), v_{\widetilde{a}}(x)+v_{\widetilde{b}}(x)-v_{\widetilde{a}}(x) v_{\widetilde{b}}(x)\right\rangle: x \in X\right\} .
\end{aligned}
$$

Let $\lambda$ be a constant, and the algorithm for $\widetilde{a}$ is as follows:

$$
\begin{aligned}
\lambda \widetilde{a} & =\left\{\left\langle 1-\left(1-\mu_{\widetilde{a}}(x)\right)^{\lambda},\left(v_{\widetilde{a}}(x)\right)^{\lambda}\right\rangle: x \in X\right\}, \\
\tilde{a}^{\lambda} & =\left\{\left\langle\left(\mu_{\widetilde{a}}(x)\right)^{\lambda}, 1-\left(1-v_{\widetilde{a}}(x)\right)^{\lambda}\right\rangle: x \in X\right\} .
\end{aligned}
$$

$$
D_{\mathrm{NE}}(\tilde{a}, \tilde{b})=\sqrt{\frac{1}{2 n} \sum_{i=1}^{n}\left[\left(\mu_{\tilde{a}}\left(x_{i}\right)-\mu_{\tilde{b}}\left(x_{i}\right)\right)^{2}+\left(\nu_{\tilde{a}}\left(x_{i}\right)-v_{\tilde{b}}\left(x_{i}\right)\right)^{2}+\left(\pi_{\tilde{a}}\left(x_{i}\right)-\pi_{\tilde{b}}\left(x_{i}\right)\right)^{2}\right]} .
$$

Definition 4. Let $\widetilde{a}$ and $\widetilde{b}$ be IFSs of the universe $X ; d(\widetilde{a}, \widetilde{b})$ represents the distance measure between $\widetilde{a}$ and $\widetilde{b} ; d(\widetilde{a}, \widetilde{b})$ must fulfil the following properties [103]:

(i) $d(\widetilde{a}, \widetilde{b}) \geq 0$

(ii) $d(\widetilde{a}, \widetilde{b})=d(\widetilde{b}, \widetilde{a})$

(iii) $d(\widetilde{a}, \widetilde{b})=0$, if and only if, $\widetilde{a}=\widetilde{b}$

(iv) If $\widetilde{a} \subseteq \widetilde{b} \subseteq \widetilde{c}$ then $d(\widetilde{a}, \widetilde{c}) \geq d(\widetilde{a}, \widetilde{b})$ and $d(\widetilde{a}, \widetilde{c}) \geq d(\widetilde{b}, \widetilde{c})$

Let $\tilde{a}=\left\{\left\langle x, \mu_{\tilde{a}}(x), v_{\tilde{a}}(x)\right\rangle: x \in X\right\}$ and $\widetilde{b}=\left\{\left\langle x, \mu_{\tilde{b}}(x)\right.\right.$, $\left.\left.v_{b}(x)\right\rangle: x \in X\right\}$, and the normalized Euclidean distance $D_{\mathrm{NE}}(\tilde{a}, \tilde{b})$ between $\tilde{a}$ and $\tilde{b}$ can be represented in the following way [104]:
Definition 5. Assume there are $k$ decision makers in the decision procedure, $\widetilde{w}^{*}=\left(\widetilde{w}_{1}^{*}, \widetilde{w}_{2}^{*}, \ldots, \widetilde{w}_{k}^{*}\right)$ is the weight of a group of decision makers, where $\sum_{d=1}^{k} \widetilde{w}_{d}^{*}=1$. In order to integrate all decision makers' opinion into a group decision opinion, the Intuitionistic Fuzzy Weighted Averaging (IFWA) operator can be represented in the following way [32]:

$$
\begin{aligned}
r_{i j} & =\operatorname{IFWA}_{\widetilde{w}^{*}}\left(r_{i j}^{(1)}, r_{i j}^{(2)}, \ldots, r_{i j}^{(k)}\right) \\
& =\widetilde{w}_{1}^{*} r_{i j}^{(1)} \oplus \widetilde{w}_{2}^{*} r_{i j}^{(2)} \oplus \widetilde{w}_{3}^{*} r_{i j}^{(3)} \oplus \cdots \oplus \widetilde{w}_{k}^{*} r_{i j}^{(k)} \\
& =\left[1-\prod_{d=1}^{k}\left(1-\mu_{i j}^{d}\right)^{\widetilde{w}_{d}^{*}}, \prod_{d=1}^{k}\left(v_{i j}^{d}\right)^{\widetilde{w}_{d}^{*}}\right] .
\end{aligned}
$$

where $r_{i j}^{(k)}$ represents an intuitionistic performance value in $k$ th expert matrix and $r_{i j}$ is the intuitionistic performance value aggregated by the all experts' weights.

4.2. Best-Worst Method. Best-worst method was proposed by Rezaei [105], which simplified the calculation process. BWM optimizes the comparison way, turning secondary comparisons into reference comparisons. Analytic Hierarchy Process (AHP), which is similar to the BWM principle, has more $\left(n^{2}-5 n-6\right) / 2$ times of comparison.

Step 1: gather experts to discuss a common set of decision criteria $\left(C_{1}, C_{2}, \ldots, C_{m}\right)$.

Step 2: select the best (most important) and worst (least important) criteria, respectively.

Step 3: calculate the preference of the best criterion over all the other criteria by number 1 to $9 . a_{i j}>1$ represents $i$ is more important than $j$, the importance of $i$ to $j$ increases as the number increases. The result is recorded as Best-to-Others:

$$
A_{B}=\left(a_{B 1}, a_{B 2}, \ldots, a_{B m}\right) .
$$

Step 4: calculate the preference of all the criteria over the worst criterion by number 1 to 9 , and the result is recorded as Others-to-Worst:

$$
A_{W}=\left(a_{1 W}, a_{2 W}, \ldots, a_{m W}\right)^{T},
$$

where $a_{i i}=1$

Step 5: compute the optimal criteria weight by the following formula:

$$
\begin{aligned}
& \text { s.t. } \\
& \left|\frac{w_{B}}{w_{j}}-a_{B j}\right| \leq \xi, \quad \text { for all } j, \\
& \left|\frac{w_{j}}{w_{W}}-a_{j W}\right| \leq \xi, \quad \text { for all } j, \\
& \sum_{j} w_{j}=1, w_{j} \geq 0, \quad \text { for all } j .
\end{aligned}
$$

By solving the above inequalities, the final criteria weight $w_{j}=\left(w_{1}, w_{2}, \ldots, w_{m}\right)$ was obtained.

4.3. WASPAS Method. WASPAS method was proposed by Chakraborty and Zvadskas in 2004, which was a dominant MCGDM method integrating the weighted sum model (WSM) and weighted product model (WPM) [75]. Compared with WSM and WPM, WASPAS could provide more accurate results and simplify the calculation process [106], so it has become a more efficient tool for dealing with MCGDM problems. Assuming that $w_{j}$ is weight of $j$ th criterion, $x_{i j}$ denotes the performance value of $i$ th alternative according to the $j$ th criterion $(i=1,2, \ldots, n$ and $j=1,2, \ldots, m)$. The WASPAS method steps are as follows: 
Step 1: calculate the linear normalization of performance values as follows:

$$
\bar{x}_{i j}= \begin{cases}\frac{x_{i j}}{\max _{i} x_{i j}}, & \text { if } j \in C_{b}, \\ \frac{\min _{i} x_{i j}}{x_{i j}}, & \text { if } j \in C_{n},\end{cases}
$$

where $C_{b}$ and $C_{n}$ are the sets of the beneficial and nonbeneficial criteria.

Step 2: compute the measures of WSM $\left(Q_{i}^{(1)}\right)$ and WPM $\left(Q_{i}^{(2)}\right)$ for each alternative as follows:

$$
\begin{gathered}
Q_{i}^{(1)}=\sum_{j=1}^{m} w_{j} \bar{x}_{i j}, \\
Q_{i}^{(2)}=\prod_{j=1}^{m}\left(\bar{x}_{i j}\right)^{w_{j}} .
\end{gathered}
$$

Step 3: obtain the aggregated measures of the WASPAS method for each alternative as follows:

$$
Q_{i}=\lambda Q_{i}^{(1)}+(1-\lambda) Q_{i}^{(2)},
$$

where $\lambda$ represents the parameter of the WASPAS method and $\lambda \in[0,1]$. When $\lambda=1$, the WASPAS method is transformed to WSM, and $\lambda=0$; it is transformed to WPM.

Step 4: rank the alternatives according to decreasing values of $Q_{i}$.

4.4. TOPSIS Method. TOPSIS was proposed by Hwang and Yoon [71], as a classical MCGDM problem processing method. Its principle is to make the final solution as close as possible to PIS (positive ideal solution) and away from NIS (negative ideal solution). The TOPSIS method steps are as follows:

Step 1: normalize the decision matrix as follows:

$$
r_{i j}=\frac{x_{i j}}{\sqrt{\sum_{k=1}^{n} x_{k j}^{2}}},
$$

where $x_{i j}$ is the performance value (crisp number) in decision matrix and $r_{i j}$ denotes the normalized value, $i \in\{1,2, \ldots, n\}$ and $j \in\{1,2, \ldots, m\}$.

Step 2: aggregate the criteria weights to the normalized matrix by the following:

$$
v_{i j}=w_{j} r_{i j}
$$

Step 3: obtain the $v_{j}^{+}$(PIS) and $v_{j}^{-}$(NIS) for each criterion as follows:

$$
\begin{gathered}
v_{j}^{+}= \begin{cases}\max \left\{v_{1 j}, v_{2 j}, \ldots, v_{n j}\right\}, & \text { if } j \in C_{b}, \\
\min \left\{v_{1 j}, v_{2 j}, \ldots, v_{n j}\right\}, & \text { if } j \in C_{n},\end{cases} \\
v_{j}^{-}= \begin{cases}\max \left\{v_{1 j}, v_{2 j}, \ldots, v_{n j}\right\}, & \text { if } j \in C_{b}, \\
\max \left\{v_{1 j}, v_{2 j}, \ldots, v_{n j}\right\}, & \text { if } j \in C_{n},\end{cases}
\end{gathered}
$$

where $C_{b}$ and $C_{n}$ are the sets of the beneficial and nonbeneficial criteria.

Step 4: compute the separation measures for each alternative as follows:

$$
\begin{aligned}
& S_{i}^{+}=\sqrt{\sum_{j=1}^{m}\left(v_{j}^{+}-v_{i j}\right)^{2}}, \quad i=1,2, \ldots, n, \\
& S_{i}^{-}=\sqrt{\sum_{j=1}^{m}\left(v_{j}^{-}-v_{i j}\right)^{2},} \quad i=1,2, \ldots, n .
\end{aligned}
$$

Step 5: obtain the closeness coefficient of each alternative to the ideal solution as follows:

$$
\mathrm{CC}_{i}=\frac{S_{i}^{-}}{S_{i}^{-}+S_{i}^{+}}
$$

where the value of $\mathrm{CC}_{i}$ is bigger and the alternative $A_{i}$ is better.

\section{The Proposed Method}

The proposed method consists of the following three steps: (1) Preparation stage: It constructs the decision-making group to determine the criteria, alternatives, and intuitionistic fuzzy set. After that each expert establishes the fuzzy decision matrix. (2) Computation stage: weigh the criteria by the BWM method after the discussion of experts. Then, aggregate the priori given expert weights into the fuzzy decision matrix by the IFWA operator. (3) Selection stage: after calculating the WASPAS measures of each alternative, the fuzzy TOPSIS is integrated into this step. Fuzzy positive/negative ideal solutions are computed; finally, the closeness coefficient of each alternatives is obtained. Figure 1 represents the conceptual framework of the proposed method.

Suppose that there are a set of $n$ alternatives $\left(A_{1}, A_{2}, \ldots, A_{n}\right)$, a set of $m$ criteria $\left(C_{1}, C_{2}, \ldots, C_{m}\right)$, and a set of $k$ decision makers $\left(D_{1}, D_{2}, \ldots, D_{k}\right)$. The proposed method is as follows: 


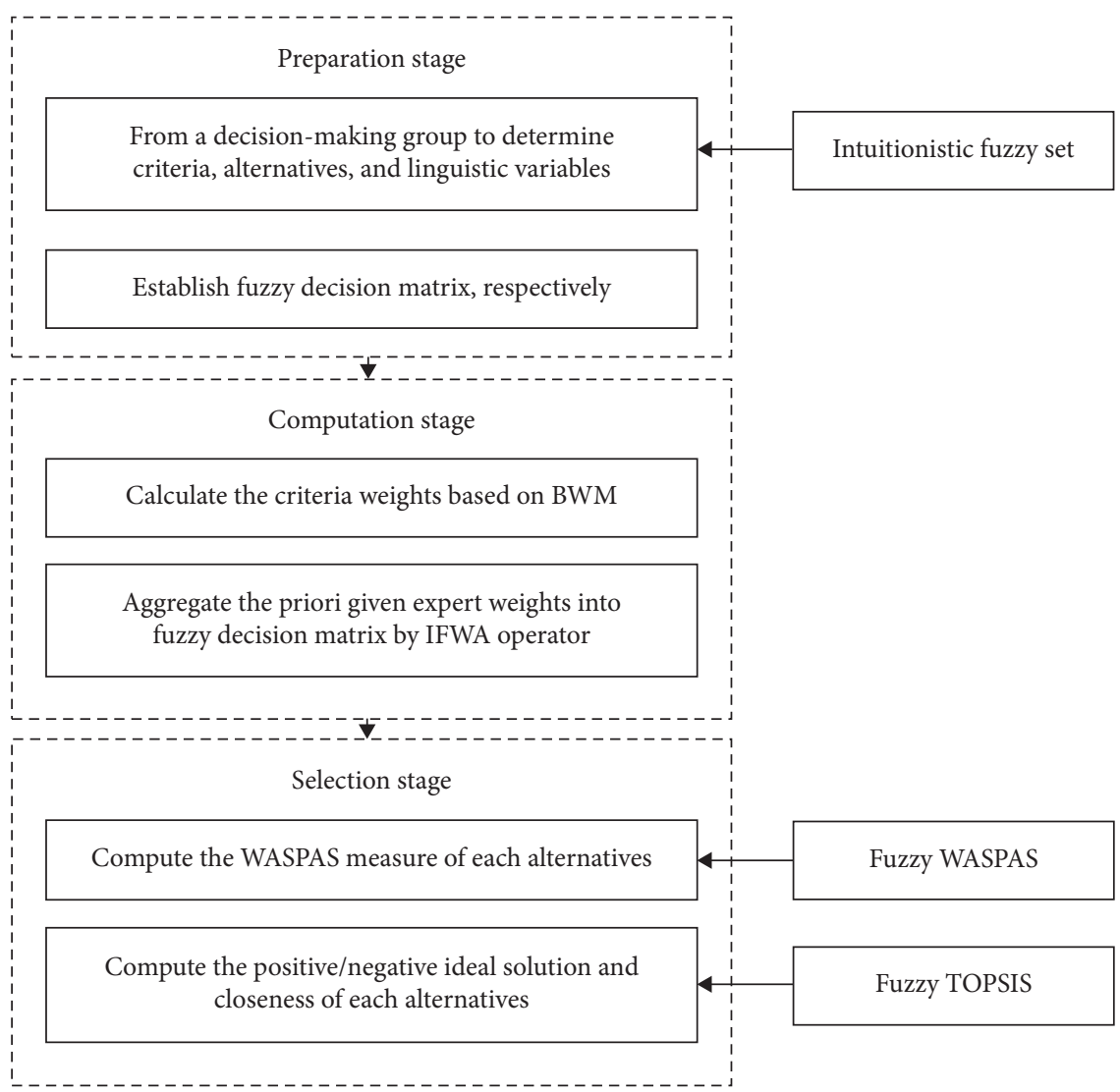

Figure 1: The conceptual framework of the proposed method.

Step 1: a group of decision makers select the best (most important) and worst (least important) criteria after discussion.

Step 2: calculate the Best-to-Others and Others-toWorst by number 1 to 9 :

$$
\begin{aligned}
A_{B} & =\left(a_{B 1}, a_{B 2}, \ldots, a_{B m}\right), \\
A_{W} & =\left(a_{1 W}, a_{2 W}, \ldots, a_{m W}\right)^{T} .
\end{aligned}
$$

Step 3: compute the optimal criteria weight by equation (10) and obtain

$$
w_{j}^{*}=\left(w_{1}^{*}, w_{2}^{*}, \ldots, w_{m}^{*}\right)
$$

Step 4: construct the fuzzy decision matrix $\mathrm{DM}^{(d)}$ of the $d$ th decision maker as follows:

$$
\begin{aligned}
& \begin{array}{lllll}
C_{1} & C_{2} & \ldots & C_{m}
\end{array} \\
& \mathrm{DM}^{(d)}=\left(\widetilde{x}_{i j}^{d}\right)_{n \times m}=\begin{array}{c}
A_{1} \\
A_{2} \\
\vdots \\
A_{n}
\end{array}\left[\begin{array}{cccc}
\tilde{x}_{11}^{d} & \widetilde{x}_{12}^{d} & \ldots & \widetilde{x}_{1 m}^{d} \\
\tilde{x}_{21}^{d} & \tilde{x}_{22}^{d} & \ldots & \tilde{x}_{2 m}^{d} \\
\vdots & \vdots & \ddots & \vdots \\
\widetilde{x}_{n 1}^{d} & \widetilde{x}_{n 2}^{d} & \ldots & \widetilde{x}_{n m}^{d}
\end{array}\right], \quad d=1, \ldots, k,
\end{aligned}
$$

where $\widetilde{x}_{i j}^{d}$ is an intuitionistic fuzzy set, and it denotes the performance value of the alternative $A_{i}$ on the criterion $C_{j}$ by decision maker $D_{d}, 1 \leq i \leq n, 1 \leq j \leq m$, and $1 \leq d \leq k$. In addition, experts use the linguistic terms [107] to evaluate the alternatives as shown in Table 3.

Step 5: aggregate the decision group weights $\widetilde{w}^{*}=\left(\widetilde{w}_{1}^{*}, \widetilde{w}_{2}^{*}, \ldots, \widetilde{w}_{k}^{*}\right)$ into the fuzzy decision matrix $\mathrm{DM}^{(d)}$ by the IFWA operator in equation (7) and obtain the fuzzy average decision matrix DM, where $\sum_{d=1}^{k} \widetilde{w}_{d}^{*}=1$ :

$$
\begin{aligned}
& \begin{array}{llll}
C_{1} & C_{2} & \ldots & C_{m}
\end{array} \\
& \left.\mathrm{DM}=\left(\widetilde{x}_{i j}\right)_{n \times m}=\begin{array}{c}
A_{1} \\
A_{2} \\
\vdots \\
A_{n}
\end{array} \begin{array}{cccc}
\tilde{x}_{11} & \tilde{x}_{12} & \ldots & \tilde{x}_{1 m} \\
\tilde{x}_{21} & \tilde{x}_{22} & \ldots & \tilde{x}_{2 m} \\
\vdots & \vdots & \ddots & \vdots \\
\tilde{x}_{n 1} & \tilde{x}_{n 2} & \ldots & \tilde{x}_{n m}
\end{array}\right] \text {, }
\end{aligned}
$$

where $\widetilde{x}_{i j}$ is an intuitionistic fuzzy set, and it represents the average performance value of the alternative $A_{i}$ on the criterion $C_{j}$ by all decision makers, $1 \leq i \leq n$, $1 \leq j \leq m$.

Step 6: calculate the normalized performance values by the following equation: 
TABLE 3: Linguistic terms and corresponding IFNs.

\begin{tabular}{lc}
\hline Linguistic terms & Intuitionistic fuzzy numbers $(\mu, \nu)$ \\
\hline Extremely good (EG) & $(1.00,0.00)$ \\
Very very good (VVG) & $(0.90,0.10)$ \\
Very good (VG) & $(0.80,0.10)$ \\
Good (G) & $(0.70,0.20)$ \\
Medium good (MG) & $(0.60,0.30)$ \\
Fair (F) & $(0.50,0.40)$ \\
Medium poor (MP) & $(0.40,0.50)$ \\
Poor (P) & $(0.25,0.60)$ \\
Very poor (VP) & $(0.10,0.75)$ \\
Very very poor (VVP) & $(0.10,0.90)$
\end{tabular}

$$
\widetilde{s}_{i j} \begin{cases}\frac{\tilde{x}_{i j}}{\max _{i} \tilde{x}_{i j}}=\frac{\left(u_{i j}, v_{i j}\right)}{\left(\max _{i} u_{i j}, \min _{i} v_{i j}\right)}, & \text { if } j \in C_{b}, \\ \frac{\min _{i} \tilde{x}_{i j}}{\tilde{x}_{i j}}=\frac{\left(\min _{j} u_{i j}, \max _{i} v_{i j}\right)}{\left(u_{i j}, v_{i j}\right)}, & \text { if } j \in C_{n},\end{cases}
$$

and the normalized fuzzy decision matrix $\overline{\mathrm{DM}}$ can be obtained:

$$
\begin{aligned}
& \begin{array}{llll}
C_{1} & C_{2} & \ldots & C_{m}
\end{array} \\
& \overline{\mathrm{DM}}=\left(\widetilde{s}_{i j}\right)_{n \times m}=\begin{array}{c}
A_{1} \\
A_{2} \\
\vdots \\
A_{n}
\end{array}\left[\begin{array}{cccc}
\widetilde{s}_{11} & \widetilde{s}_{12} & \ldots & \widetilde{s}_{1 m} \\
\widetilde{s}_{21} & \widetilde{s}_{22} & \ldots & \widetilde{s}_{2 m} \\
\vdots & \vdots & \ddots & \vdots \\
\widetilde{s}_{n 1} & \widetilde{s}_{n 2} & \ldots & \widetilde{s}_{n m}
\end{array}\right]
\end{aligned}
$$

where $\widetilde{s}_{i j}$ denotes the normalized performance value and $C_{b}$ and $C_{n}$ are the sets of the beneficial and nonbeneficial criteria.

Step 7: compute the measures of WSM $\left(\widetilde{Q}_{i}^{(1)}\right)$ for each alternative in equation (12) as follows:

$$
\begin{aligned}
\widetilde{Q}_{i}^{(1)} & =\sum_{j=1}^{m} w_{j}^{*} \widetilde{s}_{i j}=\widetilde{Q}_{i 1}^{(1)} \oplus \widetilde{Q}_{i 2}^{(1)} \oplus \cdots \oplus \widetilde{Q}_{i m}^{(1)} \\
& =\left(w_{1}^{*} \otimes \widetilde{s}_{i 1}\right) \oplus\left(w_{2}^{*} \otimes \widetilde{s}_{i 2}\right) \oplus \cdots \oplus\left(w_{m}^{*} \otimes \widetilde{s}_{i m}\right),
\end{aligned}
$$

where $w_{j}^{*}$ represents average weight of the $j$ th criterion from all decision makers.

Step 8: calculate the measures of WPM $\left(\widetilde{Q}_{i}^{(2)}\right)$ for each alternative in equation (13) as follows:

$$
\widetilde{Q}_{i}^{(2)}=\prod_{j=1}^{m}\left(\widetilde{s}_{i j}\right)^{w_{j}^{*}}=\widetilde{Q}_{i 1}^{(2)} \otimes \widetilde{Q}_{i 2}^{(2)} \otimes \cdots \otimes \widetilde{Q}_{i m}^{(2)}=\left(\widetilde{s}_{i 1}\right)^{w_{1}^{*}} \otimes\left(\widetilde{s}_{i 2}\right)^{w_{2}^{*}} \otimes \cdots \otimes\left(\widetilde{s}_{i m}\right)^{w_{m}^{*}}
$$

Step 9: obtain the WASPAS measures of each alternative by the result of steps 7 and 8 :

$$
\widetilde{Q}_{i}=\lambda \widetilde{Q}_{i}^{(1)}+(1-\lambda) \widetilde{Q}_{i}^{(2)},
$$

where criterion $C_{j}$ of alternative $A_{i}$ measure as follows:

$$
\widetilde{Q}_{i j}=\lambda \widetilde{Q}_{i j}^{(1)}+(1-\lambda) \widetilde{Q}_{i j}^{(2)}
$$

$$
\begin{aligned}
& \widetilde{v}_{j}^{+}= \begin{cases}\max \left\{\widetilde{Q}_{1 j}, \widetilde{Q}_{2 j}, \ldots, \widetilde{Q}_{n j}\right\}=\left(\max _{j} u_{i j}, \min _{j} v_{i j}\right)=\left(u_{j}^{+}, v_{j}^{+}\right), & \text {if } j \in C_{b}, \\
\min \left\{\widetilde{Q}_{1 j}, \widetilde{Q}_{2 j}, \ldots, \widetilde{Q}_{n j}\right\}=\left(\min _{j} u_{i j}, \max _{j} v_{i j}\right)=\left(u_{j}^{+}, v_{j}^{+}\right), & \text {if } j \in C_{n},\end{cases} \\
& \widetilde{v}_{j}^{-}= \begin{cases}\min \left\{\widetilde{Q}_{1 j}, \widetilde{Q}_{2 j}, \ldots, \widetilde{Q}_{n j}\right\}=\left(\min _{j} u_{i j}, \max _{j} v_{i j}\right)=\left(u_{j}^{-}, v_{j}^{-}\right), & \text {if } j \in C_{b}, \\
\max \left\{\widetilde{Q}_{1 j}, \widetilde{Q}_{2 j}, \ldots, \widetilde{Q}_{n j}\right\}=\left(\max _{j} u_{i j}, \min _{j} v_{i j}\right)=\left(u_{j}^{-}, v_{j}^{-}\right), & \text {if } j \in C_{n} .\end{cases}
\end{aligned}
$$


Step 11: compute the distance from each alternative to

$\widetilde{v}_{j}^{+} / \widetilde{v}_{j}^{-}$according to equation (6) as follows:

$$
\begin{aligned}
& D_{i}^{+}=D\left(\widetilde{v}_{j}^{+}, \widetilde{Q}_{i j}\right)=\sqrt{\frac{1}{2 m} \sum_{j=1}^{m}\left[\left(\mu_{j}^{+}-\mu_{i j}\right)^{2}+\left(v_{j}^{+}-v_{i j}\right)^{2}+\left(\pi_{j}^{+}-\pi_{i j}\right)^{2}\right]}, \\
& D_{i}^{-}=D\left(\widetilde{v}_{j}^{-}, \widetilde{Q}_{i j}\right)=\sqrt{\frac{1}{2 m} \sum_{j=1}^{m}\left[\left(\mu_{j}^{-}-\mu_{i j}\right)^{2}+\left(v_{j}^{-}-v_{i j}\right)^{2}+\left(\pi_{j}^{-}-\pi_{i j}\right)^{2}\right]},
\end{aligned}
$$

where $D_{i}^{+}$denotes the distance between the alternative $A_{i}$ and the positive ideal solution $\widetilde{v}_{j}^{+}$.

Step 12: calculate the closeness coefficient of each alternative to the ideal solution as follows:

$$
\mathrm{CC}_{i}=\frac{D_{i}^{-}}{D_{i}^{-}+D_{i}^{+}},
$$

where the higher value of $\mathrm{CC}_{i}$ represents that the $i$ th alternative is better.

\section{Comparing the Proposed Approach with Other Methods}

WASPAS, integrating the WAM and WPM model, has the advantage of higher accuracy. In addition, the WASPAS overcomes the complex multiplication calculation and becomes a convenient MCGDM method. However, through previous studies, it was found that the improved accuracy of ranking value and uncertain expression of performance value were usually ignored in the application of WASPAS and weighting the criteria was also complex. By improving some typical hybrid methods, the ranking value accuracy is increased. The hesitancy is taken into decision matrix, and a concise method to calculate criteria weight is chosen.

The main differences between the hybrid method proposed in this paper and other related methods are as follows. (1) WASPAS and TOPSIS are integrated to improve accuracy in the ranking stage so that the alternatives ranking results are closer to the decision makers' idea. (2) Intuitionistic fuzzy sets are used in the process to provide experts with freedom to express the hesitation, and it is another dimension besides the affirmation and negation.
(3) The determination of criteria weights is simpler and clearer. Compared with the classical comparison method, BWM can simplify the steps and reduce the computational difficulty.

\section{Illustrative Examples and Discussion}

7.1. Illustrative Example. In this paper, $\mathrm{H}$ company's resilient-green supplier selection in supply chain environment was taken as an example. Assuming that three decision makers $\left(d_{1}, d_{2}, d_{3}\right)$ evaluate four alternatives (suppliers) $\left(A_{1}, A_{2}, A_{3}, A_{4}\right), \mathrm{H}$ company provided three decision makers' weights $(0.3,0.3,0.4)$ according to different functions. Each decision matrix must contain all the indicators, including $G_{1}$-eco-design, $G_{2}$-green procurement, $G_{3}$-pollution production, $G_{4}$-green Packing, $G_{5}$-green image, $G_{6}$-life cycle management, $S_{1}$-surplus inventory, $S_{2}$-factory segregation, $S_{3}$-reliability, $S_{4}$-reorganization, $\mathrm{O}_{1}$-logistics, $\mathrm{O}_{2}$-warehousing, and $\mathrm{O}_{3}$-cooperation commitment.

Step 1. Decision makers consult to select the most important $\left(G_{3}\right)$ and least important $\left(\mathrm{O}_{2}\right)$ criteria, respectively.

Step 2. Calculate the Best-to-Others and Others-toWorst by number 1 to 9 , as shown in Tables 4 and 5:

$$
\begin{gathered}
A_{B}=(6,5,1,7,4,2,3,4,6,7,2,8,4), \\
A_{W}=(5,4,8,4,6,7,7,7,5,6,8,1,5)^{T} .
\end{gathered}
$$

Step 3. Obtain the optimal criteria weight by equation (10):

$$
w_{j}^{*}=(0.085,0.03,0.244,0.028,0.063,0.089,0.085,0.089,0.041,0.063,0.112,0.022,0.049)
$$

Step 4. The three experts construct the decision matrix separately. The linguistic terms used in the matrix are shown in Table 3: 
TABLE 4: Pairwise comparison vector for the best criterion.

\begin{tabular}{lccccccccccccc}
\hline Criteria & $G_{1}$ & $G_{2}$ & $G_{3}$ & $G_{4}$ & $G_{5}$ & $G_{6}$ & $S_{1}$ & $S_{2}$ & $S_{3}$ & $S_{4}$ & $O_{1}$ & $O_{2}$ & $O_{3}$ \\
\hline Best criterion $G_{3}$ & 6 & 5 & 1 & 7 & 4 & 2 & 3 & 4 & 6 & 7 & 2 & 8 & 4 \\
\hline
\end{tabular}

TABle 5: Pairwise comparison vector for the worst criterion.

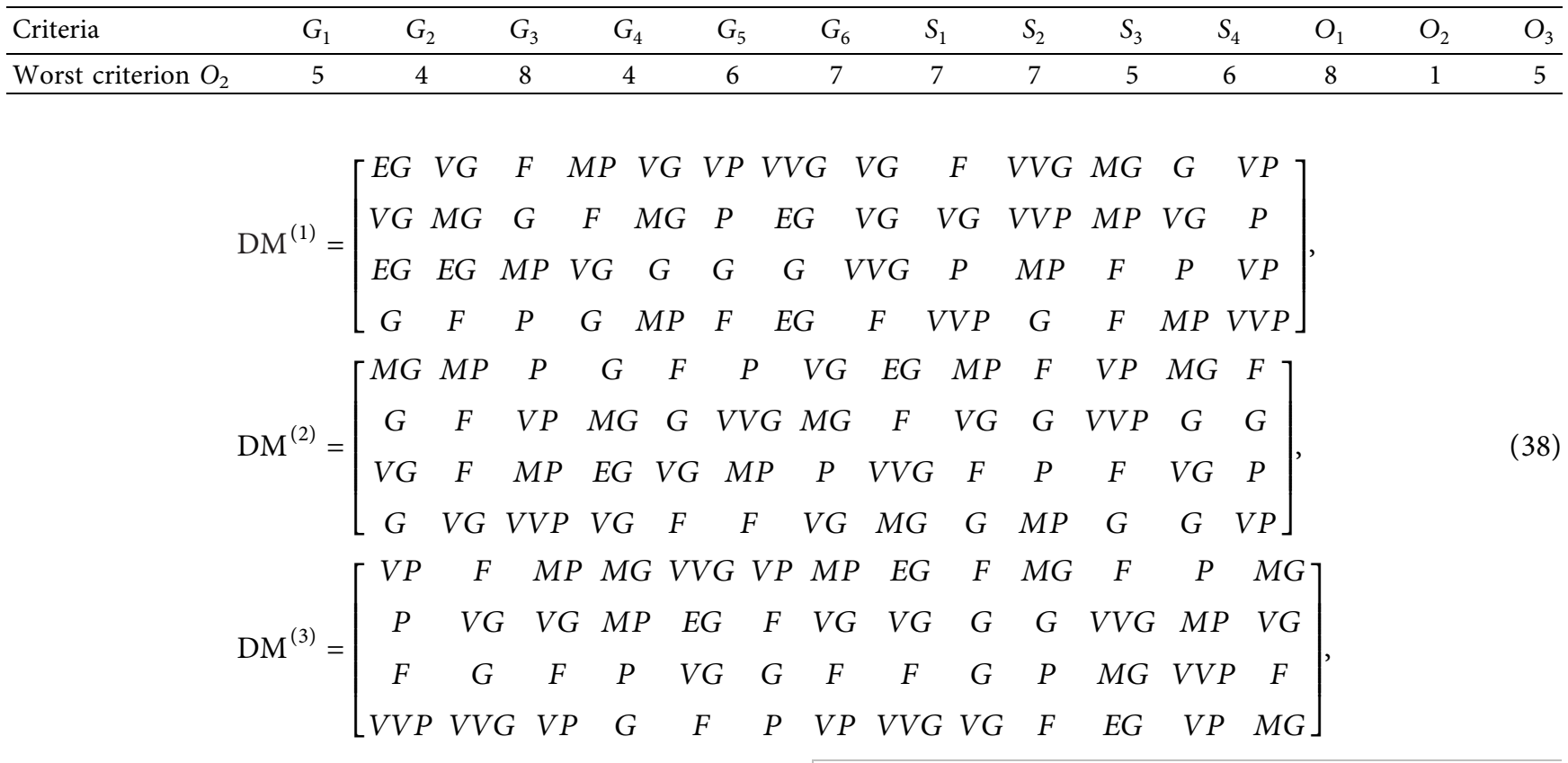

where linguistic terms can be transferred to the intuitionistic fuzzy numbers by Table 3 .

Step 5. Aggregate the decision group weights $\widetilde{w}^{*}=(0.3,0.3,0.4)$ into the fuzzy decision matrix
$\mathrm{DM}^{(d)}$ by IFWA operator in equation (7), and obtain the fuzzy average decision matrix DM as follows:

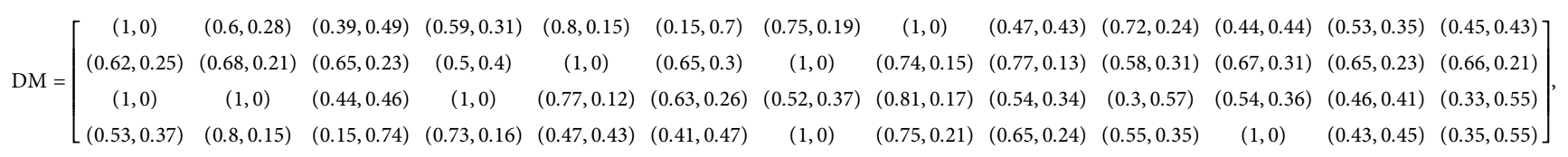

where

$$
\begin{aligned}
\tilde{x}_{12}= & {\left[1-\prod_{d=1}^{3}\left(1-\mu_{i j}^{d}\right)^{\tilde{w}_{d}^{*}}, \prod_{d=1}^{3}\left(v_{i j}^{d}\right)^{\tilde{w}_{d}^{*}}\right] } \\
= & {\left[1-(1-0.8)^{0.3} *(1-0.4)^{0.3} *(1-0.5)^{0.4},(0.1)^{0.3}\right.} \\
& \left.*(0.5)^{0.3} *(0.4)^{0.4}\right] \\
= & (0.6,0.28) .
\end{aligned}
$$

Step 6. Normalize the performance values by equation (24), and the normalized fuzzy decision matrix $\overline{\mathrm{DM}}$ is obtained. Table 6 contains performance values in the $\overline{\mathrm{DM}}$.

Step 7. Compute the measures of WSM $\left(\widetilde{Q}_{i j}^{(1)}\right)$ and WPM $\left(\widetilde{Q}_{i j}^{(2)}\right)$ for each criterion $C_{j}$ of alternative $A_{i}$ by equations (27) and (28). Tables 7 and 8 represent the WSM and WPM measures of each performance value, respectively.

$\widetilde{Q}_{12}^{(2)}=\left(\widetilde{s}_{i 2}\right)^{w_{2}^{*}}=(0.6,0.28)^{0.03}=(0.985,0.01)$.

Step 8. According to equation (30), the WASPAS measures are obtained, as shown in Table 9, and $\lambda=0.5$ is set in this paper: 
TABLE 6: The normalized performance values in the average decision matrix.

\begin{tabular}{|c|c|c|c|c|}
\hline Criteria & $A_{1}$ & $A_{2}$ & $A_{3}$ & $A_{4}$ \\
\hline$G_{1}$ & $(1,0)$ & $\begin{array}{l}(0.617, \\
0.252)\end{array}$ & $(1,0)$ & $\begin{array}{l}(0.534, \\
0.365)\end{array}$ \\
\hline$G_{2}$ & $\begin{array}{l}(0.599 \\
0.282)\end{array}$ & $\begin{array}{l}(0.676, \\
0.211)\end{array}$ & $(1,0)$ & $(0.8,0.152)$ \\
\hline$G_{3}$ & $\begin{array}{c}(0.393 \\
0.494)\end{array}$ & $\begin{array}{l}(0.645 \\
0.225)\end{array}$ & $\begin{array}{l}(0.442, \\
0.457)\end{array}$ & $\begin{array}{c}(0.148 \\
0.741)\end{array}$ \\
\hline$G_{4}$ & $(0.586,0.31)$ & $(0.497,0.4)$ & $(1,0)$ & $\begin{array}{c}(0.734, \\
0.163)\end{array}$ \\
\hline$G_{5}$ & $(0.8,0.152)$ & $(1,0)$ & $\begin{array}{l}(0.774, \\
0.123)\end{array}$ & $\begin{array}{l}(0.472, \\
0.428)\end{array}$ \\
\hline$G_{6}$ & $(0.148,0.7)$ & $\begin{array}{l}(0.652, \\
0.298)\end{array}$ & $(0.631,0.26)$ & $(0.412,0.47)$ \\
\hline$S_{1}$ & $(0.748,0.19)$ & $(1,0)$ & $\begin{array}{l}(0.516 \\
0.367)\end{array}$ & $(1,0)$ \\
\hline$S_{2}$ & $(1,0)$ & $\begin{array}{l}(0.737 \\
0.152)\end{array}$ & $(0.81,0.174)$ & $\begin{array}{c}(0.754, \\
0.211)\end{array}$ \\
\hline$S_{3}$ & $\begin{array}{c}(0.472, \\
0.428)\end{array}$ & $\begin{array}{c}(0.765 \\
0.132)\end{array}$ & $(0.54,0.342)$ & $\begin{array}{c}(0.645, \\
0.238)\end{array}$ \\
\hline$S_{4}$ & $\begin{array}{l}(0.718 \\
0.235)\end{array}$ & $\begin{array}{c}(0.583 \\
0.314)\end{array}$ & $\begin{array}{c}(0.299 \\
0.568)\end{array}$ & $\begin{array}{l}(0.547, \\
0.347)\end{array}$ \\
\hline$O_{1}$ & $\begin{array}{c}(0.442, \\
0.443)\end{array}$ & $(0.67,0.313)$ & $\begin{array}{l}(0.543, \\
0.357)\end{array}$ & $(1,0)$ \\
\hline $\mathrm{O}_{2}$ & $\begin{array}{c}(0.528, \\
0.351)\end{array}$ & $(0.65,0.234)$ & $\begin{array}{l}(0.457, \\
0.412)\end{array}$ & $\begin{array}{c}(0.427 \\
0.447)\end{array}$ \\
\hline $\mathrm{O}_{3}$ & $\begin{array}{c}(0.455 \\
0.431)\end{array}$ & $\begin{array}{l}(0.664, \\
0.211)\end{array}$ & $\begin{array}{l}(0.326, \\
0.546)\end{array}$ & $(0.35,0.55)$ \\
\hline
\end{tabular}

$\widetilde{s}_{12}=\left(\widetilde{x}_{12} / \max _{1} \widetilde{x}_{12}\right)=(0.6,0.28) /(1,0)=(0.6,0.28)$.

TABLE 7: The WSM measures of each performance value.

\begin{tabular}{|c|c|c|c|c|}
\hline Criteria & $A_{1}$ & $A_{2}$ & $A_{3}$ & $A_{4}$ \\
\hline$G_{1}$ & $(1,0)$ & $(0.078,0.89)$ & $(1,0)$ & $\begin{array}{l}(0.063, \\
0.918)\end{array}$ \\
\hline$G_{2}$ & $\begin{array}{l}(0.027 \\
0.963)\end{array}$ & $\begin{array}{l}(0.033, \\
0.954)\end{array}$ & $(1,0)$ & $\begin{array}{l}(0.047, \\
0.945)\end{array}$ \\
\hline$G_{3}$ & $\begin{array}{l}(0.115, \\
0.842)\end{array}$ & $\begin{array}{l}(0.223, \\
0.695)\end{array}$ & $\begin{array}{l}(0.133 \\
0.826)\end{array}$ & $(0.038,0.93)$ \\
\hline$G_{4}$ & $\begin{array}{l}(0.024 \\
0.968)\end{array}$ & $\begin{array}{l}(0.019 \\
0.975)\end{array}$ & $(1,0)$ & $\begin{array}{c}(0.036 \\
0.951)\end{array}$ \\
\hline$G_{5}$ & $\begin{array}{l}(0.096 \\
0.888)\end{array}$ & $(1,0)$ & $\begin{array}{l}(0.089 \\
0.876)\end{array}$ & $\begin{array}{l}(0.039 \\
0.948)\end{array}$ \\
\hline$G_{6}$ & $\begin{array}{l}(0.014, \\
0.969)\end{array}$ & $(0.09,0.898)$ & $\begin{array}{l}(0.085, \\
0.887)\end{array}$ & $\begin{array}{l}(0.046, \\
0.935)\end{array}$ \\
\hline$S_{1}$ & $\begin{array}{l}(0.111, \\
0.868)\end{array}$ & $(1,0)$ & $(0.06,0.918)$ & $(1,0)$ \\
\hline$S_{2}$ & $(1,0)$ & $\begin{array}{l}(0.112, \\
0.846)\end{array}$ & $\begin{array}{l}(0.137 \\
0.856)\end{array}$ & $\begin{array}{l}(0.117, \\
0.871)\end{array}$ \\
\hline$S_{3}$ & $\begin{array}{l}(0.026, \\
0.966)\end{array}$ & $(0.058,0.92)$ & $\begin{array}{l}(0.031, \\
0.957)\end{array}$ & $\begin{array}{l}(0.042, \\
0.943)\end{array}$ \\
\hline$S_{4}$ & $\begin{array}{c}(0.077 \\
0.913)\end{array}$ & $(0.054,0.93)$ & $\begin{array}{l}(0.022, \\
0.965)\end{array}$ & $\begin{array}{l}(0.049 \\
0.936)\end{array}$ \\
\hline$O_{1}$ & $\begin{array}{l}(0.063, \\
0.913)\end{array}$ & $\begin{array}{l}(0.117, \\
0.878)\end{array}$ & $\begin{array}{l}(0.084, \\
0.891)\end{array}$ & $(1,0)$ \\
\hline $\mathrm{O}_{2}$ & $\begin{array}{l}(0.016, \\
0.977)\end{array}$ & $\begin{array}{l}(0.023, \\
0.969)\end{array}$ & $\begin{array}{l}(0.013, \\
0.981)\end{array}$ & $\begin{array}{l}(0.012, \\
0.982)\end{array}$ \\
\hline $\mathrm{O}_{3}$ & $(0.029,0.96)$ & $\begin{array}{l}(0.052, \\
0.927)\end{array}$ & $\begin{array}{l}(0.019 \\
0.971)\end{array}$ & $\begin{array}{l}(0.021, \\
0.971)\end{array}$ \\
\hline
\end{tabular}

TABLE 8: The WPM measures of each performance value.

\begin{tabular}{lcccc}
\hline Criteria & $A_{1}$ & $A_{2}$ & $A_{3}$ & $A_{4}$ \\
\hline$G_{1}$ & $(1,0)$ & $(0.96,0.024)$ & $(1,0)$ & $(0.948$, \\
& & $(0.988$, & $(1,0)$ & $0.038)$ \\
$G_{2}$ & $(0.985,0.01)$ & $0.007)$ & 0.993, \\
& $(0.796$, & $(0.898$, & $(0.819$, & $(0.627$, \\
$G_{3}$ & $0.153)$ & $0.062)$ & $0.138)$ & $0.281)$ \\
& $(0.985,0.01)$ & $(0.981$, & $(1,0)$ & $(0.991$, \\
$G_{4}$ & $0.014)$ & $(0.984$, & $0.005)$ \\
& & 0.954, \\
$G_{5}$ & $(0.986,0.01)$ & $(1,0)$ & $0.008)$ & $0.035)$ \\
& $(0.844$, & $(0.963$, & $(0.96,0.026)$ & $(0.924$, \\
$G_{6}$ & $0.102)$ & $0.031)$ & $(0.945$, & $0.055)$ \\
& $(0.976$, & $(1,0)$ & $0.038)$ & $(1,0)$ \\
$S_{1}$ & $0.018)$ & $(0.973$, & $(0.981$, & $(0.975$, \\
& $(1,0)$ & $0.015)$ & $0.017)$ & $0.021)$ \\
$S_{2}$ & & & $(0.975$, & $(0.982$, \\
& $(0.97,0.023)$ & $(0.99,0.006)$ & $0.017)$ & $0.011)$ \\
$S_{3}$ & $(0.979$, & $(0.967$, & $(0.927$, & $(0.963$, \\
& $0.017)$ & $0.024)$ & $0.052)$ & $0.027)$ \\
$S_{4}$ & $(0.913$, & $(0.956$, & $(0.934$, & $(1,0)$ \\
\multirow{2}{*}{$O_{1}$} & $0.063)$ & $0.041)$ & $0.048)$ & $(0.982$, \\
& $(0.986,0.01)$ & $(0.991$, & $(0.983$, & $0.013)$ \\
$O_{2}$ & $(0.962$, & $(0.98,0.012)$ & $(0.947$, & $(0.95,0.038)$ \\
& $0.027)$ & & $0.038)$ & \\
$O_{3}$ & $\left.\widetilde{s}_{12}\right)=0.03 \otimes(0.6,0.28)=(0.027,0.962)$. &
\end{tabular}

TABLE 9: The WASPAS measures of each performance value.

\begin{tabular}{|c|c|c|c|c|}
\hline Criteria & $A_{1}$ & $A_{2}$ & $A_{3}$ & $A_{4}$ \\
\hline$G_{1}$ & $(1,0)$ & $\begin{array}{l}(0.808, \\
0.146)\end{array}$ & $(1,0)$ & $\begin{array}{l}(0.779, \\
0.187)\end{array}$ \\
\hline$G_{2}$ & $\begin{array}{l}(0.879, \\
0.098)\end{array}$ & $\begin{array}{l}(0.892, \\
0.082)\end{array}$ & $(1,0)$ & $\begin{array}{l}(0.918, \\
0.069)\end{array}$ \\
\hline$G_{3}$ & $\begin{array}{l}(0.575, \\
0.359)\end{array}$ & $\begin{array}{l}(0.719 \\
0.208)\end{array}$ & $\begin{array}{l}(0.604, \\
0.338)\end{array}$ & $\begin{array}{l}(0.401, \\
0.511)\end{array}$ \\
\hline$G_{4}$ & $\begin{array}{l}(0.879 \\
0.098)\end{array}$ & $\begin{array}{l}(0.864, \\
0.117)\end{array}$ & $(1,0)$ & $\begin{array}{l}(0.907, \\
0.069)\end{array}$ \\
\hline$G_{5}$ & $\begin{array}{l}(0.888, \\
0.094)\end{array}$ & $(1,0)$ & $\begin{array}{l}(0.879 \\
0.084)\end{array}$ & $(0.79,0.182)$ \\
\hline$G_{6}$ & $\begin{array}{l}(0.608, \\
0.314)\end{array}$ & $\begin{array}{l}(0.817, \\
0.167)\end{array}$ & $\begin{array}{l}(0.809, \\
0.152)\end{array}$ & $\begin{array}{l}(0.731, \\
0.227)\end{array}$ \\
\hline$S_{1}$ & $\begin{array}{l}(0.854, \\
0.125)\end{array}$ & $(1,0)$ & $\begin{array}{l}(0.773, \\
0.187)\end{array}$ & $(1,0)$ \\
\hline$S_{2}$ & $(1,0)$ & $\begin{array}{c}(0.845 \\
0.113)\end{array}$ & $(0.872,0.12)$ & $\begin{array}{l}(0.851, \\
0.135)\end{array}$ \\
\hline$S_{3}$ & $\begin{array}{l}(0.829, \\
0.149)\end{array}$ & $\begin{array}{l}(0.903, \\
0.074)\end{array}$ & $\begin{array}{l}(0.844, \\
0.128)\end{array}$ & $\begin{array}{l}(0.869, \\
0.102)\end{array}$ \\
\hline$S_{4}$ & $\begin{array}{l}(0.861, \\
0.125)\end{array}$ & $(0.823,0.15)$ & $\begin{array}{l}(0.733, \\
0.224)\end{array}$ & $\begin{array}{l}(0.812, \\
0.159)\end{array}$ \\
\hline$O_{1}$ & $(0.715,0.24)$ & $(0.803,0.19)$ & $\begin{array}{l}(0.754, \\
0.207)\end{array}$ & $(1,0)$ \\
\hline $\mathrm{O}_{2}$ & $\begin{array}{l}(0.883, \\
0.099)\end{array}$ & $\begin{array}{l}(0.906, \\
0.076)\end{array}$ & $\begin{array}{l}(0.871, \\
0.109)\end{array}$ & $\begin{array}{l}(0.867, \\
0.113)\end{array}$ \\
\hline $\mathrm{O}_{3}$ & $\begin{array}{c}(0.808 \\
0.161)\end{array}$ & $\begin{array}{c}(0.862, \\
0.106)\end{array}$ & $\begin{array}{l}(0.772, \\
0.192)\end{array}$ & $\begin{array}{l}(0.779, \\
0.192)\end{array}$ \\
\hline
\end{tabular}




$$
v_{j}^{+}= \begin{cases}\max \left\{v_{1 j}, v_{2 j}, \ldots, v_{n j}\right\}, & \text { if } j \in C_{b}, \\ \min \left\{v_{1 j}, v_{2 j}, \ldots, v_{n j}\right\}, & \text { if } j \in C_{n} .\end{cases}
$$

For example,

$$
\begin{aligned}
\widetilde{Q}_{12}= & 0.5 \widetilde{Q}_{12}^{(1)}+(1-0.5) \widetilde{Q}_{12}^{(2)}=0.5 \otimes(0.027,0.963) \oplus 0.5 \\
& \otimes(0.985,0.01)=(0.881,0.098) .
\end{aligned}
$$

Step 9. Fuzzy positive/negative ideal solutions $\left(\widetilde{v}_{j}^{+} / \widetilde{v}_{j}^{-}\right)$ from Table 9 are obtained based on equations (31) and (32) as follows:

$$
\begin{aligned}
\widetilde{v}_{j}^{+} & =\max \left\{\widetilde{Q}_{1 j}, \widetilde{Q}_{2 j}, \ldots, \widetilde{Q}_{n j}\right\}=\left(\max _{j} u_{i j}, \min _{j} v_{i j}\right) \\
& =\left(u_{j}^{+}, v_{j}^{+}\right), \\
\widetilde{v}_{j}^{-} & =\min \left\{\widetilde{Q}_{1 j}, \widetilde{Q}_{2 j}, \ldots, \widetilde{Q}_{n j}\right\}=\left(\min _{j} v_{i j}, \max _{j} u_{i j}\right) \\
& =\left(u_{j}^{-}, v_{j}^{-}\right),
\end{aligned}
$$

the $\widetilde{v}_{j}^{+} / \widetilde{v}_{j}^{-}$from four alternatives under each criterion are represented in Table 10.

Step 10. According to Table 10 and equations (33) and (34), the distance between each alternative to positive/ negative ideal solution $\left(\widetilde{v}_{j}^{+} / \widetilde{v}_{j}^{-}\right)$is calculated. Finally, obtain the closeness coefficient for ranking four alternatives. Relevant values are shown in Table 11.

According to Table 11, the alternatives are ranked as $A_{2}>A_{3}>A_{4}>A_{1}$.

7.2. Sensitivity Analysis. In the WASPAS method, $\lambda$ represents the parameter and $\lambda \in[0,1]$. How does the value of $\lambda$ affect the final order of suppliers? In order to solve the problems, the sensitivity analysis was provided. We assign different values to $\lambda$, then calculate the distance between each alternative to positive/negative ideal solution $\left(\widetilde{v}_{j}^{+} / \widetilde{v}_{j}^{-}\right)$and closeness coefficient under different conditions, so as to better carry out sensitivity analysis. The results of each alternative with different values of $\lambda$ are shown in Table 12 .

The second supplier is always considered to be the best choice, and the first supplier performs poorly in any case. There are two special cases. when $\lambda=0.8$, the third supplier is superior to the second and becomes the best. When $\lambda=0.9, A_{2}, A_{3}$, and $A_{4}$ these three suppliers are almost the same good.

7.3. Comparative Analysis. As a classical research field, there are many techniques for dealing with MCGDM problems, including TOPSIS [71], AHP [72], ANP [73], VIKOR [74], BWM [30], WASPAS [75], DEMATEL,
TABLE 10: The positive/negative ideal solution of each criterion.

\begin{tabular}{lcc}
\hline Criteria & $\widetilde{v}_{j}^{+}$ & $\widetilde{v}_{j}^{-}$ \\
\hline$G_{1}$ & $(1,0)$ & $(0.779,0.187)$ \\
$G_{2}$ & $(1,0)$ & $(0.879,0.099)$ \\
$G_{3}$ & $(0.719,0.208)$ & $(0.401,0.501)$ \\
$G_{4}$ & $(1,0)$ & $(0.863,0.117)$ \\
$G_{5}$ & $(1,0)$ & $(0.79,0.182)$ \\
$G_{6}$ & $(0.817,0.152)$ & $(0.607,0.316)$ \\
$S_{1}$ & $(1,0)$ & $(0.773,0.187)$ \\
$S_{2}$ & $(1,0)$ & $(0.845,0.135)$ \\
$S_{3}$ & $(0.903,0.074)$ & $(0.828,0.15)$ \\
$S_{4}$ & $(0.861,0.125)$ & $(0.733,0.224)$ \\
$O_{1}$ & $(1,0)$ & $(0.711,0.244)$ \\
$O_{2}$ & $(0.906,0.076)$ & $(0.867,0.113)$ \\
$O_{3}$ & $(0.862,0.106)$ & $(0.772,0.192)$ \\
\hline
\end{tabular}

TABle 11: The $D_{i}^{+}, D_{i}^{-}$, and $\mathrm{CC}_{i}$ of each alternative.

\begin{tabular}{lcccc}
\hline & $A_{1}$ & $A_{2}$ & $A_{3}$ & $A_{4}$ \\
\hline$D_{i}^{+}$ & 0.168 & 0.094 & 0.112 & 0.133 \\
$D_{i}^{-}$ & 0.096 & 0.137 & 0.109 & 0.104 \\
$\mathrm{CC}_{i}$ & 0.364 & 0.595 & 0.492 & 0.439 \\
\hline$D_{1}^{+}=\sqrt{(1 / 2 m) \sum_{j=1}^{m}\left[\left(\mu_{j}^{+}-\mu_{i j}\right)^{2}+\left(v_{j}^{+}-v_{i j}\right)^{2}+\left(\pi_{j}^{+}-\pi_{i j}\right)^{2}\right]}=0.168$.
\end{tabular}

PROM-ETHEE, and the ELECTRE [76]. In order to prove the feasibility and practicability of the method proposed in this paper, we compare the alternative ranking obtained in the above illustrative example with the results of the classical MCGDM methods. Through literature review, we find that AHP is one of the earliest methods to deal with MCGDM problems [108]. TOPSIS and VIKOR as two commonly used and well-known comparative methods, which has similar calculation logic [109]. WASPAS is a novel method which has been put forward in recent years, which has higher consistency and accuracy [31]. AHP, TOPSIS, VIKOR, and WASPAS are the popular and classical methods in recent years $[110,111]$, so we choose these four methods to compare with the proposed methods. Table 13 represents the comparison results.

In the prioritization of alternatives in Table 13, there are differences in the ranking results of various methods when the parameters change. However, most of the prioritization of alternatives prove that $A_{2}$ is the best supplier and $A_{1}$ is the worst supplier. Among this, the IF-TOPSIS and IF-AHP are consistent with the result of the method proposed in this paper. IF-VIKOR has the same ranking order when parameters change. The value of $\lambda$ in IFWASPAS greatly affects the priority. When $\lambda \in[0.1,0.5]$, the result is consistent with that of this paper. When $\lambda \geq 0.6$, the fourth alternative becomes the best choice. With the increase of the value of $\lambda$, the ranking result is constantly changing. It can be concluded that the single WASPAS method is greatly influenced by the value of $\lambda$ and has weak stability. The content of Table 12 shows that the value of $\lambda$ has little influence on the prioritization of the proposed method, so it is concluded that hybrid method we proposed can improve the accuracy and stability of ranking results. 
TABLE 12: The $D_{1}^{+}, D_{1}^{-}$, and $\mathrm{CC}_{i}$ of each alternative by each $\lambda$ value.

\begin{tabular}{|c|c|c|c|c|c|}
\hline & & $D_{i}^{+}$ & $D_{i}^{-}$ & $\mathrm{CC}_{i}$ & Prioritization of alternatives \\
\hline \multirow{4}{*}{$\lambda=0.1$} & $A_{1}$ & 0.281 & 0.934 & 0.77 & \multirow{4}{*}{$A_{2}>A_{3}>A_{4}>A_{1}$} \\
\hline & $A_{2}$ & 0.025 & 0.953 & 0.975 & \\
\hline & $A_{3}$ & 0.043 & 0.939 & 0.956 & \\
\hline & $A_{4}$ & 0.08 & 0.931 & 0.921 & \\
\hline \multirow{4}{*}{$\lambda=0.2$} & $A_{1}$ & 0.282 & 0.915 & 0.764 & \multirow{4}{*}{$A_{2}>A_{3}>A_{4}>A_{1}$} \\
\hline & $A_{2}$ & 0.034 & 0.935 & 0.965 & \\
\hline & $A_{3}$ & 0.054 & 0.919 & 0.945 & \\
\hline & $A_{4}$ & 0.088 & 0.912 & 0.912 & \\
\hline \multirow{4}{*}{$\lambda=0.3$} & $A_{1}$ & 0.285 & 0.068 & 0.192 & \multirow{4}{*}{$A_{2}>A_{3}>A_{4}>A_{1}$} \\
\hline & $A_{2}$ & 0.048 & 0.107 & 0.692 & \\
\hline & $A_{3}$ & 0.068 & 0.08 & 0.54 & \\
\hline & $A_{4}$ & 0.098 & 0.064 & 0.397 & \\
\hline \multirow{4}{*}{$\lambda=0.4$} & $A_{1}$ & 0.138 & 0.08 & 0.366 & \multirow{4}{*}{$A_{2}>A_{3}>A_{4}>A_{1}$} \\
\hline & $A_{2}$ & 0.067 & 0.12 & 0.644 & \\
\hline & $A_{3}$ & 0.087 & 0.091 & 0.513 & \\
\hline & $A_{4}$ & 0.112 & 0.081 & 0.42 & \\
\hline \multirow{4}{*}{$\lambda=0.5$} & $A_{1}$ & 0.168 & 0.096 & 0.364 & \multirow{4}{*}{$A_{2}>A_{3}>A_{4}>A_{1}$} \\
\hline & $A_{2}$ & 0.094 & 0.137 & 0.595 & \\
\hline & $A_{3}$ & 0.112 & 0.109 & 0.492 & \\
\hline & $A_{4}$ & 0.133 & 0.104 & 0.439 & \\
\hline \multirow{4}{*}{$\lambda=0.6$} & $A_{1}$ & 0.211 & 0.117 & 0.357 & \multirow{4}{*}{$A_{2}>A_{3}>A_{4}>A_{1}$} \\
\hline & $A_{2}$ & 0.132 & 0.159 & 0.546 & \\
\hline & $A_{3}$ & 0.147 & 0.134 & 0.477 & \\
\hline & $A_{4}$ & 0.164 & 0.132 & 0.447 & \\
\hline \multirow{4}{*}{$\lambda=0.7$} & $A_{1}$ & 0.364 & 0.152 & 0.365 & \multirow{4}{*}{$A_{2}>A_{3}>A_{4}>A_{1}$} \\
\hline & $A_{2}$ & 0.189 & 0.189 & 0.5 & \\
\hline & $A_{3}$ & 0.195 & 0.172 & 0.468 & \\
\hline & $A_{4}$ & 0.211 & 0.168 & 0.442 & \\
\hline \multirow{4}{*}{$\lambda=0.8$} & $A_{1}$ & 0.343 & 0.197 & 0.365 & \multirow{4}{*}{$A_{3}>A_{2}>A_{4}>A_{1}$} \\
\hline & $A_{2}$ & 0.271 & 0.23 & 0.459 & \\
\hline & $A_{3}$ & 0.262 & 0.23 & 0.468 & \\
\hline & $A_{4}$ & 0.285 & 0.216 & 0.43 & \\
\hline \multirow{4}{*}{$\lambda=0.9$} & $A_{1}$ & 0.46 & 0.399 & 0.464 & \multirow{4}{*}{$A_{2}=A_{3}=A_{4}>A_{1}$} \\
\hline & $A_{2}$ & 0.39 & 0.391 & 0.5 & \\
\hline & $A_{3}$ & 0.358 & 0.358 & 0.5 & \\
\hline & $A_{4}$ & 0.4 & 0.4 & 0.5 & \\
\hline
\end{tabular}

TABLE 13: Comparison of the alternative ranking with the classical MCGDM methods.

\begin{tabular}{lcc}
\hline Method & $\begin{array}{c}\text { Prioritization of } \\
\text { alternatives }\end{array}$ \\
\hline IF-TOPSIS & $\lambda \in[0.1,0.5]$ & $A_{2}>A_{3}>A_{4}>A_{1}$ \\
& $\lambda=0.6$ & $A_{2}>A_{3}>A_{4}>A_{1}$ \\
IF-WASPAS & $\lambda=0.7$ & $A_{4}>A_{3}>A_{2}>A_{3}$ \\
& $\lambda \in[0.8,0.9]$ & $A_{4}>A_{1}>A_{3}>A_{2}$ \\
IF-AHP & & $A_{2}>A_{3}>A_{4}>A_{1}$ \\
IF-VIKOR & $\gamma=0.3 / \gamma=0.5 / \gamma=0.8$ & $A_{2}>A_{3}>A_{1}>A_{4}$ \\
The proposed & $\lambda=0.5 \lambda=0.5$ & $A_{2}>A_{3}>A_{4}>A_{1}$ \\
method & &
\end{tabular}

7.4. Discussion. The purpose of this section is to discuss the advantages of the supplier selection method used in this paper. The method is specifically manifested in the following two aspects:
(1) The ranking results are more accurate. WASPAS method has clear logic and simple calculation process, which makes the decision results more precise. In this paper, TOPSIS is integrated at the end of WASPAS to make the alternatives closer to the positive ideal solution (PIS) and away from the negative ideal solution (NIS). In this way, the results based on WASPAS and TOPSIS are more consistent.

(2) Criteria weighting processes are improved. Compared with the traditional AHP, the BWM calculation process only involves integers, and the calculation steps are greatly reduced, which reduces the arithmetic difficulty for decision makers and improves the consistency of the results.

\section{Conclusion}

By considering the environmental protection and the globalization of the supply chain, resilient-green supplier selection has become a critical issue in the supply chain management. A supplier selection model integrating WASPAS and TOPSIS method based on intuitionistic fuzzy sets is provided. Firstly, the weights of each criteria are measured by the BWM method; secondly, the decision matrix is processed with the integrated WASPAS and TOPSIS, and the alternatives are ranked.

This paper makes two contributions to the research studies on the resilient-green supplier selection. (1) In the background of supply chain management, most scholars have established the relationship between the resilience and greenness from the perspective of supply chain design, but there are few studies focusing on the resilient-green supplier selection. According to the green manufacturing process, resilient-related characteristics, and their intersection, the resilient-green supplier selection criteria system is constructed. (2) In terms of the research methods, a hybrid decision-making method based on the intuitionistic fuzzy numbers is proposed, integrating the WASPAS and TOPSIS to reduce the uncertainty and inaccuracy in the decisionmaking process. The intuitionistic fuzzy number reflects the preferences of the decision makers more accurately and avoid the fuzziness. In addition, the decision-making system proposed can not only solve the supplier selection problem but also address the site selection, supplier segmentation, performance evaluation, and other issues.

This paper proves the validity of the decision-making model through the illustrative examples, but there are still some limitations. Firstly, the determination of criteria weight by experts was dealt with. Future research studies should mention the method of weighting experts. Secondly, the intuitionistic fuzzy numbers are only used in the ranking stage. Introduction of the fuzzy sets into the weight determination is an important work. Finally, this paper proposes a decision-making method suitable for the intuitionistic fuzzy numbers. And future research studies should be extended to the application of other fuzzy sets. 


\section{Data Availability}

All related data are included within the article.

\section{Conflicts of Interest}

The authors declare that there are no conflicts of interest regarding the publication of this article.

\section{Acknowledgments}

This work was supported by the National Natural Science Foundation Council of China under Project nos. 71862035 and 71502159; Yunnan Fundamental Research Project under grant no. 2019FB085; and Philosophy and Social Science Key Foundation of Yunnan Province under Project no. ZDZZD201904.

\section{References}

[1] J. Qin, X. Liu, and W. Pedrycz, "An extended TODIM multicriteria group decision making method for green supplier selection in interval type-2 fuzzy environment," European Journal of Operational Research, vol. 258, no. 2, pp. 626-638, 2017.

[2] C. Blome, D. Hollos, and A. Paulraj, "Green procurement and green supplier development: antecedents and effects on supplier performance," International Journal of Production Research, vol. 52, no. 1, pp. 32-49, 2014.

[3] R. Ruiz-Benitez, C. López, and J. C. Real, "Environmental benefits of lean, green and resilient supply chain management: the case of the aerospace sector," Journal of Cleaner Production, vol. 167, pp. 850-862, 2017.

[4] A. Mohammed, I. Harris, A. Soroka, and R. Nujoom, "A hybrid MCDM-fuzzy multi-objective programming approach for a G-resilient supply chain network design," Computers \& Industrial Engineering, vol. 127, pp. 297-312, 2019.

[5] M. Yavari and H. Zaker, "An integrated two-layer network model for designing a resilient green-closed loop supply chain of perishable products under disruption," Journal of Cleaner Production, vol. 230, pp. 198-218, 2019.

[6] A. Haldar, A. Ray, D. Banerjee, and S. Ghosh, "Resilient supplier selection under a fuzzy environment," International Journal of Management Science and Engineering Management, vol. 9, no. 2, pp. 147-156, 2014.

[7] S. A. Torabi, M. Baghersad, and S. A. Mansouri, "Resilient supplier selection and order allocation under operational and disruption risks," Transportation Research Part E: Logistics and Transportation Review, vol. 79, pp. 22-48, 2015.

[8] S. Hosseini and A. A. Khaled, "A hybrid ensemble and AHP approach for resilient supplier selection," Journal of Intelligent Manufacturing, vol. 30, no. 1, pp. 207-228, 2019.

[9] D. Pramanik, A. Haldar, S. C. Mondal, S. K. Naskar, and A. Ray, "Resilient supplier selection using AHP-TOPSISQFD under a fuzzy environment," International Journal of Management Science and Engineering Management, vol. 12, no. 1, pp. 45-54, 2016.

[10] S. V. Parkouhi and A. S. Ghadikolaei, "A resilience approach for supplier selection: using fuzzy analytic network process and grey VIKOR techniques," Journal of Cleaner Production, vol. 161, pp. 431-451, 2017.
[11] S. Mousakhani, S. Nazari-Shirkouhi, and A. Bozorgi-Amiri, "A novel interval type-2 fuzzy evaluation model based group decision analysis for green supplier selection problems: a case study of battery industry," Journal of Cleaner Production, vol. 168, pp. 205-218, 2017.

[12] H.-W. Lo, J. J. H. Liou, H.-S. Wang, and Y.-S. Tsai, “An integrated model for solving problems in green supplier selection and order allocation," Journal of Cleaner Production, vol. 190, pp. 339-352, 2018.

[13] S. A. S. Haeri and J. Rezaei, "A grey-based green supplier selection model for uncertain environments," Journal of Cleaner Production, vol. 221, pp. 768-784, 2019.

[14] B. M. dos Santos, L. P. Godoy, and L. M. S. Campos, "Performance evaluation of green suppliers using entropyTOPSIS-F," Journal of Cleaner Production, vol. 207, pp. 498-509, 2019.

[15] $\mathrm{Z}$. Wu and J. $\mathrm{Xu}$, "Managing consistency and consensus in group decision making with hesitant fuzzy linguistic preference relations," Omega, vol. 65, pp. 28-40, 2016.

[16] G. van Valkenhoef and T. Tervonen, "Entropy-optimal weight constraint elicitation with additive multi-attribute utility models," Omega, vol. 64, pp. 1-12, 2016.

[17] D. Wu, "Supplier selection in a fuzzy group setting: a method using grey related analysis and Dempster-Shafer theory," Expert Systems with Applications, vol. 36, no. 5, pp. 88928899, 2009.

[18] H. Li, W. Wang, L. Fan, Q. Li, and X. Chen, "A novel hybrid MCDM model for machine tool selection using fuzzy DEMATEL, entropy weighting and later defuzzification VIKOR," Applied Soft Computing, vol. 91, Article ID 106207, 2020.

[19] H.-C. Liu, M.-Y. Quan, Z. Li, and Z.-L. Wang, "A new integrated MCDM model for sustainable supplier selection under interval-valued intuitionistic uncertain linguistic environment," Information Sciences, vol. 486, pp. 254-270, 2019.

[20] D. A. Wood, "Supplier selection for development of petroleum industry facilities, applying multi-criteria decision making techniques including fuzzy and intuitionistic fuzzy TOPSIS with flexible entropy weighting," Journal of Natural Gas Science and Engineering, vol. 28, pp. 594-612, 2016.

[21] G. Sirbiladze, I. Khutsishvili, and B. Midodashvili, "Associated immediate probability intuitionistic fuzzy aggregations in MCDM," Computers \& Industrial Engineering, vol. 123, pp. 1-8, 2018.

[22] H. Garg and R. Arora, "Novel scaled prioritized intuitionistic fuzzy soft interaction averaging aggregation operators and their application to multi criteria decision making," Engineering Applications of Artificial Intelligence, vol. 71, pp. 100-112, 2018.

[23] M. O. M. Javad, M. Darvishi, and A. O. M. Javad, "Green supplier selection for the steel industry using BWM and fuzzy TOPSIS: a case study of Khouzestan steel company," Sustainable Futures, vol. 2, Article ID 100012, 2020.

[24] M. Abdel-Baset, V. Chang, A. Gamal, and F. Smarandache, "An integrated neutrosophic ANP and VIKOR method for achieving sustainable supplier selection: a case study in importing field," Computers in Industry, vol. 106, pp. 94-110, 2019.

[25] H. Garg, "Novel intuitionistic fuzzy decision making method based on an improved operation laws and its application," Engineering Applications of Artificial Intelligence, vol. 60, pp. 164-174, 2017. 
[26] Q. Wu, L. Zhou, Y. Chen, and H. Chen, "An integrated approach to green supplier selection based on the interval type-2 fuzzy best-worst and extended VIKOR methods," Information Sciences, vol. 502, pp. 394-417, 2019.

[27] E. K. Zavadskas, J. Antucheviciene, S. H. R. Hajiagha, and S. S. Hashemi, "Extension of weighted aggregated sum product assessment with interval-valued intuitionistic fuzzy numbers (WASPAS-IVIF)," Applied Soft Computing, vol. 24, pp. 1013-1021, 2014.

[28] Z. Xu and H. Liao, "Intuitionistic fuzzy analytic hierarchy process," IEEE Transactions on Fuzzy Systems, vol. 22, no. 4, pp. 749-761, 2014.

[29] J. Yuan and X. Luo, "Approach for multi-attribute decision making based on novel intuitionistic fuzzy entropy and evidential reasoning," Computers \& Industrial Engineering, vol. 135, pp. 643-654, 2019.

[30] J. Rezaei, "Best-worst multi-criteria decision-making method," Omega, vol. 53, pp. 49-57, 2015.

[31] M. Deveci, F. Canitez, and I. Gökaşar, "WASPAS and TOPSIS based interval type-2 fuzzy MCDM method for a selection of a car sharing station," Sustainable Cities and Society, vol. 41, pp. 777-791, 2018.

[32] Z. Xu, "Intuitionistic fuzzy aggregation operators," IEEE Transactions on Fuzzy Systems, vol. 15, pp. 1179-1187, 2007.

[33] Z.-X. Su, G.-P. Xia, M.-Y. Chen, and L. Wang, "Induced generalized intuitionistic fuzzy OWA operator for multiattribute group decision making," Expert Systems with Applications, vol. 39, no. 2, pp. 1902-1910, 2012.

[34] Q. Mou, Z. Xu, and H. Liao, “A graph based group decision making approach with intuitionistic fuzzy preference relations," Computers \& Industrial Engineering, vol. 110, pp. 138-150, 2017.

[35] G. W. Wei and J. M. Merigó, "Methods for strategic decisionmaking problems with immediate probabilities in intuitionistic fuzzy setting," Scientia Iranica, vol. 19, no. 6, pp. 1936-1946, 2012.

[36] F. E. Boran, S. Genç, M. Kurt, and D. Akay, "A multi-criteria intuitionistic fuzzy group decision making for supplier selection with TOPSIS method," Expert Systems with Applications, vol. 36, no. 8, pp. 11363-11368, 2009.

[37] S.-F. Zhang and S.-Y. Liu, "A GRA-based intuitionistic fuzzy multi-criteria group decision making method for personnel selection," Expert Systems with Applications, vol. 38, no. 9, pp. 11401-11405, 2011.

[38] R. B. Handfield, S. V. Walton, L. K. Seegers, and S. A. Melnyk, “"Green” value chain practices in the furniture industry," Journal of Operations Management, vol. 15, no. 4, pp. 293-315, 1997.

[39] Q. Zhu, J. Sarkis, and Y. Geng, "Green supply chain management in China: pressures, practices and performance," International Journal of Operations \& Production Management, vol. 25, no. 5, pp. 449-468, 2005.

[40] S. H'mida and S. Y. Lakhal, "A model for assessing the greenness effort in a product supply chain," International Journal of Global Environmental Issues, vol. 7, pp. 4-24, 2010.

[41] S. Y. Lee and R. D. Klassen, "Drivers and enablers that foster environmental management capabilities in small- and medium-sized suppliers in supply chains," Production Operations Management, vol. 17, pp. 573-586, 2010.

[42] H.-M. Wee, M.-C. Lee, J. C. P. Yu, and C. E. Wang, "Optimal replenishment policy for a deteriorating green product: life cycle costing analysis," International Journal of Production Economics, vol. 133, no. 2, pp. 603-611, 2011.
[43] I. Gavronski, R. D. Klassen, S. Vachon, and L. F. M. D. Nascimento, "A resource-based view of green supply management," Transportation Research Part E: Logistics and Transportation Review, vol. 47, no. 6, pp. 872-885, 2011.

[44] A. Parmigiani, R. D. Klassen, and M. V. Russo, "Efficiency meets accountability: performance implications of supply chain configuration, control, and capabilities," Journal of Operations Management, vol. 29, no. 3, pp. 212-223, 2011.

[45] A. A. Hervani, M. M. Helms, and J. Sarkis, "Performance measurement for green supply chain management," Benchmarking: An International Journal, vol. 12, no. 4, pp. 330-353, 2005.

[46] S. K. Srivastava, "Green supply-chain management: a stateof-the-art literature review," International Journal of Management Reviews, vol. 9, pp. 53-80, 2010.

[47] A. E. Saadany, M. Y. Jaber, and M. Bonney, "Environmental performance measures for supply chains," Management Research Review, vol. 34, pp. 1202-1221, 2011.

[48] Z. Wu and M. Pagell, "Balancing priorities: decision-making in sustainable supply chain management," Journal of OPerations Management, vol. 29, no. 6, pp. 577-590, 2011.

[49] J. Sarkis, Q. Zhu, and K.-H. Lai, “An organizational theoretic review of green supply chain management literature," International Journal of Production Economics, vol. 130, no. 1, pp. 1-15, 2011.

[50] R. Liang and J.-Q. Wang, "A linguistic intuitionistic cloud decision support model with sentiment analysis for product selection in E-commerce," International Journal of Fuzzy Systems, vol. 21, no. 3, pp. 963-977, 2019.

[51] R. Handfield, S. V. Walton, R. Sroufe, and S. A. Melnyk, "Applying environmental criteria to supplier assessment: a study in the application of the analytical hierarchy process," European Journal of Operational Research, vol. 141, no. 1, pp. 70-87, 2002.

[52] W.-H. Tsai and S.-J. Hung, "A fuzzy goal programming approach for green supply chain optimisation under activitybased costing and performance evaluation with a value-chain structure," International Journal of Production Research, vol. 47, no. 18, pp. 4991-5017, 2009.

[53] G. Akman, "Evaluating suppliers to include green supplier development programs via fuzzy c-means and VIKOR methods," Computers \& Industrial Engineering, vol. 86, pp. 69-82, 2015.

[54] J.-J. Peng, C. Tian, W.-Y. Zhang, S. Zhang, and J.-Q. Wang, "An integrated multi-criteria decision-making framework for sustainable supplier selection under picture fuzzy environment," Technological and Economic Development of Economy, vol. 26, no. 3, pp. 573-598, 2020.

[55] P. Ji, H.-Y. Zhang, and J.-Q. Wang, "Selecting an outsourcing provider based on the combined MABAC-ELECTRE method using single-valued neutrosophic linguistic sets," Computers \& Industrial Engineering, vol. 120, pp. 429-441, 2018.

[56] A. Amindoust, "A resilient-sustainable based supplier selection model using a hybrid intelligent method," Computers \& Industrial Engineering, vol. 126, pp. 122-135, 2018.

[57] A. Chavooshi, A. A. Bahmani, A. Darijani, A. Mootab Saei, E. Mehrabi, and M. Gholipour, "The role of wood and paper industries management of Iran in sustainable development," Journal of Conservation and Utilization of Natural Resources, vol. 1, pp. 79-95, 2012.

[58] F. Sabouhi, M. S. Pishvaee, and M. S. Jabalameli, "Resilient supply chain design under operational and disruption risks 
considering quantity discount: a case study of pharmaceutical supply chain," Computers \& Industrial Engineering, vol. 126, pp. 657-672, 2018.

[59] C. S. Holling, "Resilience and stability of ecological systems," Annual Review of Ecology and Systematics, vol. 4, no. 1, pp. 1-23, 1973.

[60] S. Hosseini, N. Morshedlou, D. Ivanov, M. D. Sarder, K. Barker, and A. A. Khaled, "Resilient supplier selection and optimal order allocation under disruption risks," International Journal of Production Economics, vol. 213, pp. 124-137, 2019.

[61] S. Y. Ponomarov and M. C. Holcomb, "Understanding the concept of supply chain resilience," The International Journal of Logistics Management, vol. 20, no. 1, pp. 124-143, 2009.

[62] E. Brandon-Jones, B. Squire, C. W. Autry, and K. J. Petersen, "A contingent resource-based perspective of supply chain resilience and robustness," Journal of Supply Chain Management, vol. 50, pp. 55-73, 2014.

[63] D. Ivanov and B. Sokolov, "Control and system-theoretic identification of the supply chain dynamics domain for planning, analysis and adaptation of performance under uncertainty," European Journal of Operational Research, vol. 224, no. 2, pp. 313-323, 2013.

[64] Y. Sheffi and B. R. James, "A supply chain view of the resilient enterprise," MIT Sloan Management Review, vol. 47, pp. 41-48, 2005.

[65] R. Rajesh and V. Ravi, "Supplier selection in resilient supply chains: a grey relational analysis approach," Journal of Cleaner Production, vol. 86, pp. 343-359, 2015.

[66] S. G. Azevedo, K. Govindan, H. Carvalho, and V. CruzMachado, "Ecosilient index to assess the greenness and resilience of the upstream automotive supply chain," Journal of Cleaner Production, vol. 56, pp. 131-146, 2013.

[67] M. Sonia, L. Young, and M. Muhammad, "Sustainable and resilient supply chain network design under disruption risks," Sustainability, vol. 6, pp. 6666-6686, 2014.

[68] B. Fahimnia and A. Jabbarzadeh, "Marrying supply chain sustainability and resilience: a match made in heaven," Transportation Research Part E: Logistics and Transportation Review, vol. 91, pp. 306-324, 2016.

[69] B. Zahiri, J. Zhuang, and M. Mohammadi, "Toward an integrated sustainable-resilient supply chain: a pharmaceutical case study," Transportation Research Part E: Logistics and Transportation Review, vol. 103, pp. 109-142, 2017.

[70] J. J. H. Liou and G.-H. Tzeng, "Comments on "multiple criteria decision making (MCDM) methods in economics: an overview"' Technological and Economic Development of Economy, vol. 18, no. 4, pp. 672-695, 2012.

[71] C.-L. Hwang and K. Yoon, "Introduction," Multiple Attribute Decision Making, vol. 186, pp. 1-15, 1981.

[72] T. L. Saaty, "A scaling method for priorities in hierarchical structures," Journal of Mathematical Psychology, vol. 15, no. 3, pp. 234-281, 1977.

[73] T. L. Saaty, Decision Making with Dependence and Feedback: The Analytic Network Process, RWS Publications, Pittsburgh, PA, USA, 1996.

[74] S. Opricovic, Multicriteria Optimization of Civil Engineering System, Faculty of Civil Engineering, Belgrade, Serbia, 1998.

[75] E. K. Zavadskas, Z. Turskis, J. Antucheviciene, and A. Zakarevicius, "Optimization of weighted aggregated sum product assessment," Elektron Elektrotech, vol. 122, pp. 3-6, 2012.
[76] B. Roy, "Classement et choix en présence de points de vue multiples," Revue Française d'Informatique et de Recherche Opérationnelle, vol. 2, no. 8, pp. 57-75, 1968.

[77] D. Kannan, A. B. L. D. S. Jabbour, and C. J. C. Jabbour, "Selecting green suppliers based on GSCM practices: using fuzzy TOPSIS applied to a Brazilian electronics company," European Journal of Operational Research, vol. 233, no. 2, pp. 432-447, 2014.

[78] H. Gupta and M. K. Barua, "Supplier selection among SMEs on the basis of their green innovation ability using BWM and fuzzy TOPSIS," Journal of Cleaner Production, vol. 152, pp. 242-258, 2017.

[79] L. Demir, M. E. Akpınar, C. Araz, and M. A. Ilgın, "A green supplier evaluation system based on a new multi-criteria sorting method: VIKORSORT," Expert Systems with Applications, vol. 114, pp. 479-487, 2018.

[80] S. Gupta, U. Soni, and G. Kumar, "Green supplier selection using multi-criterion decision making under fuzzy environment: a case study in automotive industry," Computers \& Industrial Engineering, vol. 136, pp. 663-680, 2019.

[81] M. Keshavarz Ghorabaee, E. K. Zavadskas, M. Amiri, and A. Esmaeili, "Multi-criteria evaluation of green suppliers using an extended WASPAS method with interval type-2 fuzzy sets," Journal of Cleaner Production, vol. 137, pp. 213-229, 2016.

[82] R.-J. Lin, "Using fuzzy DEMATEL to evaluate the green supply chain management practices," Journal of Cleaner Production, vol. 40, pp. 32-39, 2013.

[83] R. J. Kuo, Y. C. Wang, and F. C. Tien, "Integration of artificial neural network and MADA methods for green supplier selection," Journal of Cleaner Production, vol. 18, no. 12, pp. 1161-1170, 2010.

[84] J. Luan, Z. Yao, F. Zhao, and X. Song, "A novel method to solve supplier selection problem: hybrid algorithm of genetic algorithm and ant colony optimization," Mathematics and Computers in Simulation, vol. 156, pp. 294-309, 2019.

[85] A. Zouggari and L. Benyoucef, "Simulation based fuzzy TOPSIS approach for group multi-criteria supplier selection problem," Engineering Applications of Artificial Intelligence, vol. 25, no. 3, pp. 507-519, 2012.

[86] R.-X. Nie, Z.-P. Tian, J.-Q. Wang, H.-Y. Zhang, and T.-L. Wang, "Water security sustainability evaluation: applying a multistage decision support framework in industrial region," Journal of Cleaner Production, vol. 196, pp. 16811704, 2018.

[87] S. H. Hashemi, A. Karimi, and M. Tavana, "An integrated green supplier selection approach with analytic network process and improved Grey relational analysis," International Journal of Production Economics, vol. 159, pp. 178-191, 2015.

[88] M.-L. Tseng, M. S. Islam, N. Karia, F. A. Fauzi, and S. Afrin, "A literature review on green supply chain management: trends and future challenges," Resources, Conservation and Recycling, vol. 141, pp. 145-162, 2019.

[89] S.-B. Tsai, Y.-M. Wei, K.-Y. Chen, L. Xu, P. Du, and H.-C. Lee, "Evaluating green suppliers from a green environmental perspective," Environment and Planning B: Planning and Design, vol. 43, no. 5, pp. 941-959, 2016.

[90] R. M. Vanalle, G. M. D. Ganga, M. G. Filho, and W. C. Lucato, "Green supply chain management: an investigation of pressures, practices, and performance within the Brazilian automotive supply chain," Journal of Cleaner Production, vol. 151, pp. 250-259, 2017. 
[91] V. K. Sharma, P. Chandna, and A. Bhardwaj, "Green supply chain management related performance indicators in agro industry: a review," Journal of Cleaner Production, vol. 141, pp. 1194-1208, 2017.

[92] J. Johansson, H. Hassel, and E. Zio, "Reliability and vulnerability analyses of critical infrastructures: comparing two approaches in the context of power systems," Reliability Engineering \& System Safety, vol. 120, pp. 27-38, 2013.

[93] J. Johansson and H. Hassel, "An approach for modelling interdependent infrastructures in the context of vulnerability analysis," Reliability Engineering \& System Safety, vol. 95, no. 12, pp. 1335-1344, 2010.

[94] G. Scur and M. E. Barbosa, "Green supply chain management practices: multiple case studies in the Brazilian home appliance industry," Journal of Cleaner Production, vol. 141, pp. 1293-1302, 2017.

[95] H. Carvalho, K. Govindan, S. G. Azevedo, and V. CruzMachado, "Modelling green and lean supply chains: an ecoefficiency perspective," Resources, Conservation and Recycling, vol. 120, pp. 75-87, 2017.

[96] G. Zhang and Z. Zhao, "Green packaging management of logistics enterprises," Physics Procedia, vol. 24, pp. 900-905, 2012.

[97] K. Govindan, S. Rajendran, J. Sarkis, and P. Murugesan, "Multi criteria decision making approaches for green supplier evaluation and selection: a literature review," Journal of Cleaner Production, vol. 98, pp. 66-83, 2015.

[98] Öy Uygun and A. Dede, "Performance evaluation of green supply chain management using integrated fuzzy multicriteria decision making techniques," Computers \& Industrial Engineering, vol. 102, pp. 502-511, 2016.

[99] F. Ç9rn and İ Otay, "A two-stage fuzzy approach for supplier evaluation and order allocation problem with quantity discounts and lead time," Information Sciences, vol. 339, pp. 143-157, 2016.

[100] S. Hosseini and K. Barker, "A Bayesian network model for resilience-based supplier selection," International Journal of Production Economics, vol. 180, pp. 68-87, 2016.

[101] L. A. Zadeh, "Fuzzy sets," Information and Control, vol. 8, no. 3, pp. 338-353, 1965.

[102] K. T. Atanassov, "Intuitionistic fuzzy sets," Fuzzy Sets and Systems, vol. 20, no. 1, pp. 87-96, 1986.

[103] W. Wang and X. Xin, "Distance measure between intuitionistic fuzzy sets," Pattern Recognition Letters, vol. 26, no. 13, pp. 2063-2069, 2005.

[104] E. Szmidt and J. Kacprzyk, "Distances between intuitionistic fuzzy sets," Fuzzy Sets and Systems, vol. 114, no. 3, pp. 505-518, 2000.

[105] J. Rezaei, "Best-worst multi-criteria decision-making method: some properties and a linear model," Omega, vol. 64, pp. 126-130, 2015.

[106] K. A. Alam, R. Ahmed, F. S. Butt, S.-G. Kim, and K.-M. Ko, "An uncertainty-aware integrated fuzzy AHP-WASPAS model to evaluate public cloud computing services," Procedia Computer Science, vol. 130, pp. 504-509, 2018.

[107] A. Memari, A. Dargi, M. R. A. Jokar, R. Ahmad, and A. R. A. Rahim, "Sustainable supplier selection: a multicriteria intuitionistic fuzzy TOPSIS method," Journal of Manufacturing Systems, vol. 50, pp. 9-24, 2019.

[108] J. Falak, M. Kunjan, D. Nagaraju, and S. Narayanan, "Evaluation of continuous improvement techniques using hybrid MCDM technique under fuzzy environment," Materials Today: Proceedings, vol. 22, pp. 1295-1305, 2020.
[109] N. Ploskas and J. Papathanasiou, "A decision support system for multiple criteria alternative ranking using TOPSIS and VIKOR in fuzzy and nonfuzzy environments," Fuzzy Sets and Systems, vol. 377, pp. 1-30, 2019.

[110] S. Bid and G. Siddique, "Human risk assessment of Panchet Dam in India using TOPSIS and WASPAS multi-criteria decision-making (MCDM) methods," Heliyon, vol. 5, Article ID e01956, 2019.

[111] L. Suganthi, "Multi expert and multi criteria evaluation of sectoral investments for sustainable development: an integrated fuzzy AHP, VIKOR/DEA methodology," Sustainable Cities and Society, vol. 43, pp. 144-156, 2018. 